UNIVERSIDADE ESTADUAL PAULISTA “JULIO DE MESQUITA FILHO” FACULDADE DE CIÊNCIAS AGRÁRIAS E VETERINÁRIAS CÂMPUS DE JABOTICABAL

\title{
SUSCETIBILIDADE MAGNÉTICA PARA A ESTIMATIVA DE ATRIBUTOS DO SOLO E MAPEAMENTO DE ÁREAS SOB CULTIVO DE CANA-DE-AÇÚCAR.
}

\section{Diego Silva Siqueira}

Orientador: Prof. Dr. José Marques Júnior Co-Orientador: Prof. Dr. Gener Tadeu Pereira

Dissertação apresentada à Faculdade de Ciências Agrárias e Veterinárias - Unesp, Campus de Jaboticabal, como parte das exigências para a obtenção do título de Mestre em Agronomia (Produção Vegetal).

JABOTICABAL - SÃO PAULO - BRASIL

Fevereiro - 2010 


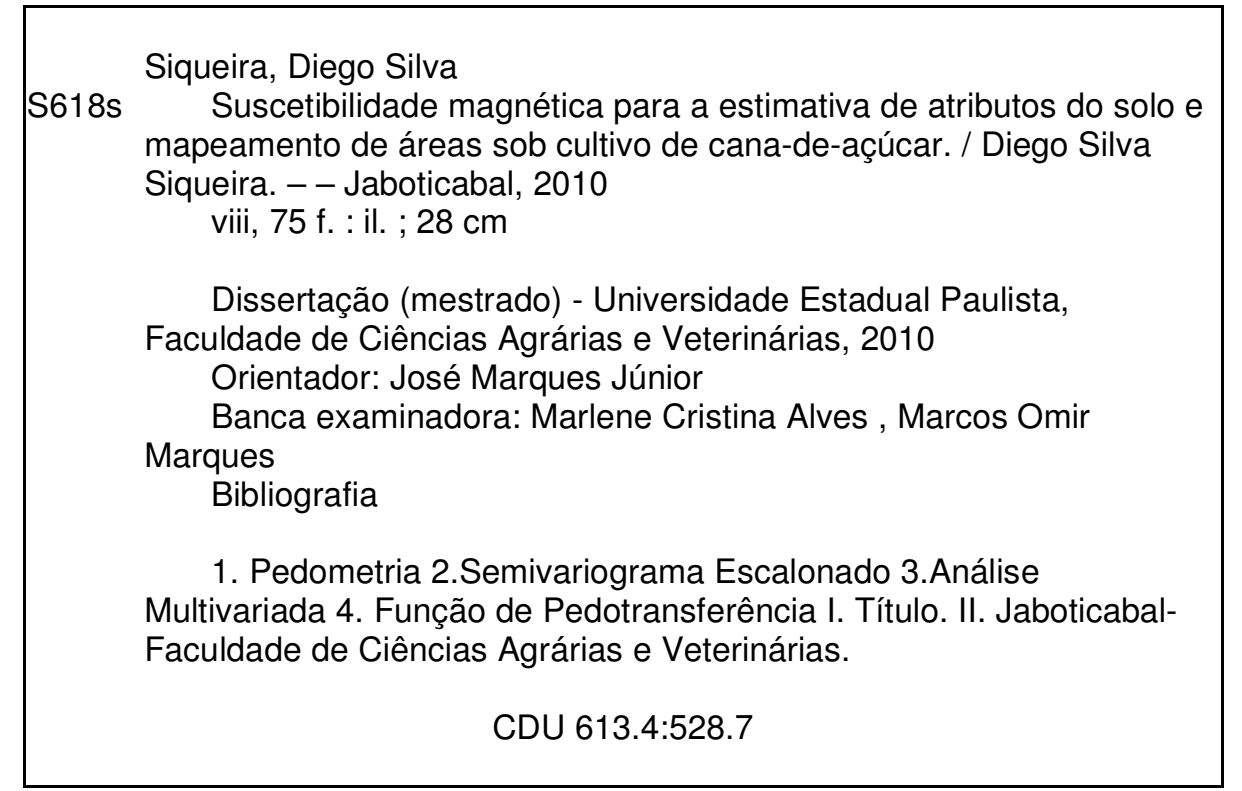

Ficha catalográfica elaborada pela Seção Técnica de Aquisição e Tratamento da Informação Serviço Técnico de Biblioteca e Documentação - UNESP, Câmpus de Jaboticabal. 


\section{CERTIFICADO DE APROVAÇÃO}

TíTLO: SUSCETIBILIDADE MAGNETICA PARA A ESTIMATIVA DE ATRIBUTOS DO SOlO E MAPEAMENTO DE ÁREAs SOB CULTIVo DE CANA-DE-AÇŨCAR.

AUTOR: DIEGO SILVA SIQUEIRA

ORIENTADOR: Prof. Dr. JOSE MARQUES JUNIOR

Aprovado como parte das exigéncias para obtençăo do Título de MESTRE em AGRONOMIA (PRODUÇÄO VEGETAL), pela Comissăo Examinadora:

Prof. Dr. JOSE MARQUESS JUNIOR

Departamento de Solos e Adubos / Faculdade de Ciências Agrárias e Veterinárias de Jaboticabal

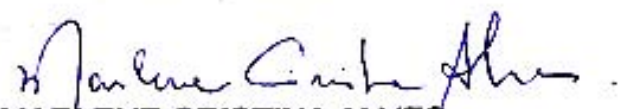

Profa. Dra. MARLENE CRISTINA ALVES

Departamento de Fitossanidade. Engerharia Rural e Solos / Faculdade de Engenharia de litha Solteira

Prof. Dr. MARCOS OMIR MARQUES

Departamento de Tecpológia / Faculdade de Ciências Agrárias e Veterinárias de Jaboticabal

Data da realizaçăo: 25 de fevereiro de 2010. 


\section{DADOS CURRICULARES DO AUTOR}

DIEGO SILVA SIQUEIRA - nascido em 21 de fevereiro de 1984 em Ribeirão Preto SP, graduado em Engenharia Agronômica pela Universidade Estadual Paulista Júlio de Mesquita Filho (2008). Foi bolsista de iniciação científica no período de 2003 a 2007. Atualmente é aluno de Mestrado do curso de Pós-Graduação em Agronomia Produção Vegetal pela FCAV/UNESP Jaboticabal (Bolsista FAPESP). Atua na área de Agronomia, com ênfase em Gênese, Morfologia e Classificação dos Solos, trabalhando principalmente nos seguintes temas: geoestatística, análise multivariada, mapeamento de áreas de manejo específico com base na relação solo-relevo, técnicas pedométricas e classificação númerica. Membro ativo do grupo de pesquisa Caracterização do Solo para fins de Manejo Específico (CSME) da UNESP Câmpus de Jaboticabal. 
"Faça as coisas o mais simples que você puder, porém não se restrinja às mais simples”

(Albert Einstein)

\section{DEDICO}

Ao eterno amigo Rafael Camargo Pereira (in memoriam) pelo exemplo de dedicação, humildade e honestidade. Saudades!

"Tem que ser água!”

\section{OFEREÇO}

A toda minha família em especial aos meus pais (Lázaro Donizete Siqueira e Rosângela Silva Siqueira) a minha irmã (Natalia Silva Siqueira), por sempre me apoiarem e aos meus tios (Archimedes Belon e Maria Lucia da Silva Belon) e aos meus avôs (Joaquim Maria da Silva e Luzia Ferreira da Silva) por serem presentes e atuantes em todas as fases de minha vida. 


\section{AGRADECIMENTOS}

A Deus pela benção da vida, amparo nos momentos difíceis, força e coragem nos momentos de fraqueza e pela oportunidade de realizar esse feito.

Ao Prof. Dr. José Marques Júnior e ao Prof. Dr. Gener Tadeu Pereira pela confiança nesses 7 anos de orientação desde a graduação, convivência, ensinamentos, e acima de tudo por compartilharem de momentos únicos como verdadeiros amigos.

Aos amigos da Iniciação Científica e Pós-Graduação Diogo Mazza Barbieri, Livia Arantes Camargo, Sammy Sidney Rocha Matias, Alan Panosso, Daniel Júnior Andrade, Renata Gimenes, Vanessa Curi Galati, Hélio Francisco da Silva Neto, Gustavo de Nobrega Romani, Rafael Golçaves Peluco, Lucas Cortez, lara Caroline Gobi e Cesar de Souza Pirajá Figueiredo pelo apoio, troca de experiências, histórias e risadas; também agradeço a Alessandra Evelin Tormena pela dedicação, carinho e paciência.

A todos os amigos dentro e fora da universidade, especialmente aos amigos da Usina São Martinho e do Departamento de Ciências Exatas e Solos e Adubos, responsáveis por parte da minha formação pessoal, científica e profissional.

À Fundação de Amparo à Pesquisa do Estado de São Paulo - FAPESP- pela concessão da bolsa de estudos.

À Usina São Martinho pela concessão da área de estudos. 


\section{SUMÁRIO}

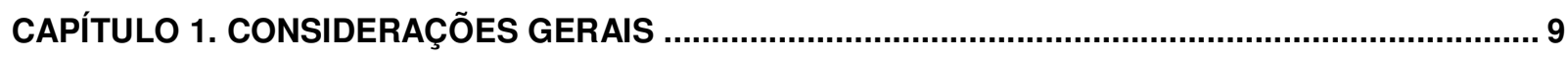

1.1 INTRODUÇÃO

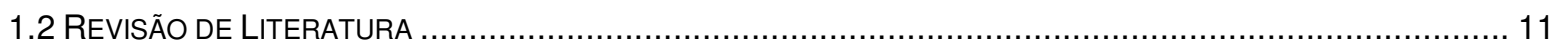

1.2.1 Levantamento de solos, variabilidade dos atributos do solo e áreas de manejo específico .... 11

1.2.2 Suscetibilidade magnética na determinação indireta de atributos do solo .............................. 16

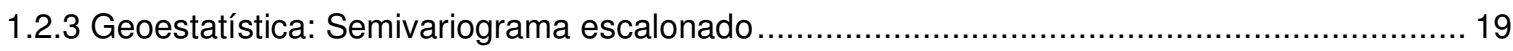

1.2.4 Análise multivariada na área de ciências agrárias ......................................................... 22

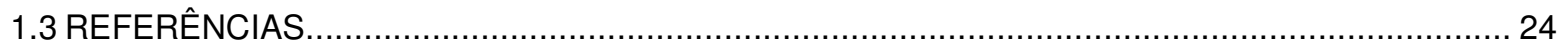

\section{CAPÍTULO 2. ESTIMATIVA DOS ATRIBUTOS DO SOLO UTILIZANDO A SUSCETIBILIDADE}

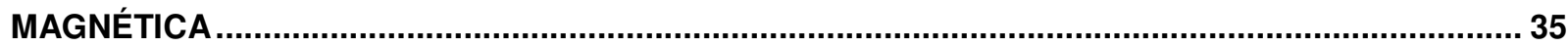

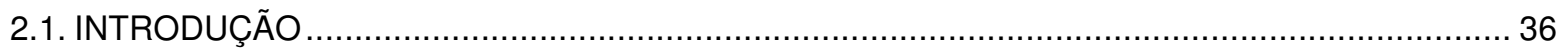

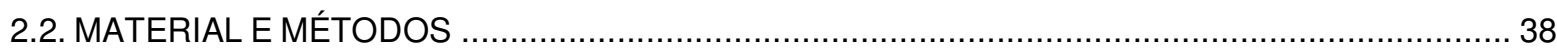

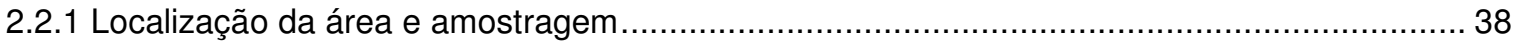

2.2.2 Avaliação dos atributos do solo e análise dos dados .......................................................... 38

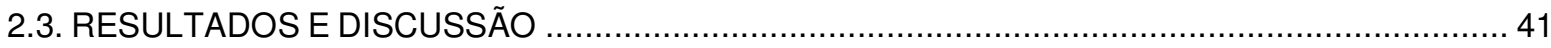

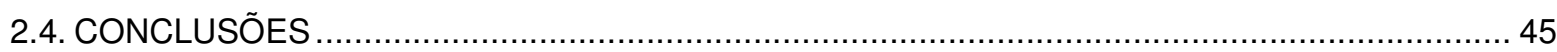

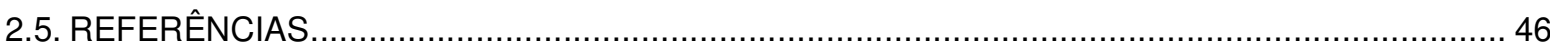

\section{CAPÍTULO 3. MAPEAMENTO DE ÁREAS DE MANEJO ESPECÍFICO PARA A CANA-DE-AÇÚCAR}

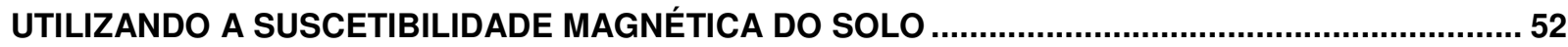

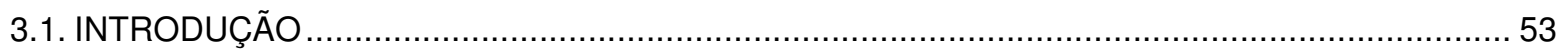

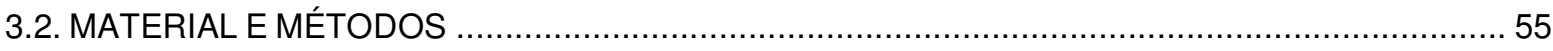

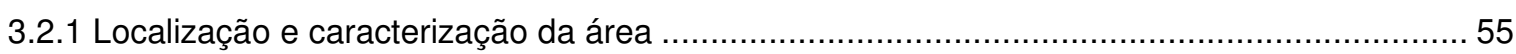

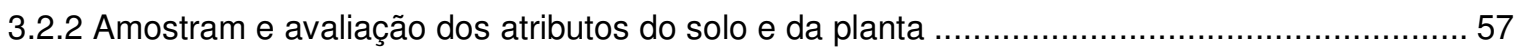

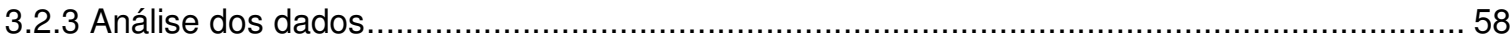

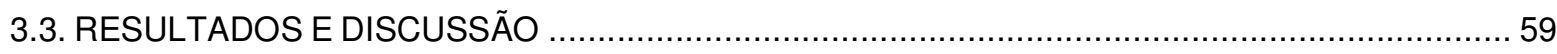

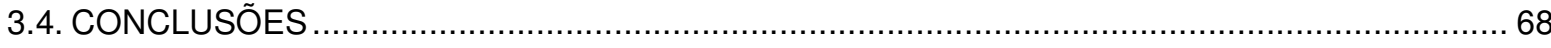

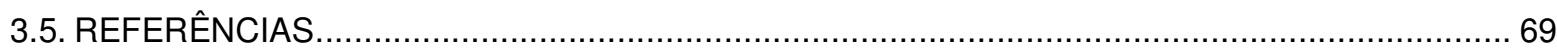




\section{SUSCETIBILIDADE MAGNÉTICA PARA A ESTIMATIVA DE ATRIBUTOS DO SOLO E MAPEAMENTO DE ÁREAS SOB CULTIVO DE CANA-DE-AÇÚCAR}

RESUMO - O objetivo deste estudo foi avaliar o potencial da suscetibilidade magnética para estimar atributos do solo e mapear áreas de manejo especifico para a cultura da cana-de-açúcar. Dois experimentos foram realizados. No primeiro, foram amostrados 50 pontos de forma aleatória em uma área de $2 \mathrm{ha}$, na profundidade de 0,00-0,20 $\mathrm{m}$. Foi construída uma curva de calibração para converter as leituras das amostras de solo feitas na balança em medidas de suscetibilidade magnética. A suscetibilidade magnética medida por uma balança analítica teve uma correlação de $0,58 \mathrm{com}$ o teor de argila, $-0,75$ com o teor de matéria orgânica, 0,41 com a saturação por bases e 0,82 com o teor de hematita do solo na profundidade 0,00-0,20 m. A análise estatística multivariada dos componentes principais mostrou que a suscetibilidade magnética explica $10,69 \%$ da variância do conjunto de atributos do solo estudados. No segundo experimento, foram retiradas aleatoriamente (grade irregular) 110 amostras em uma área de 770 ha em duas profundidades, 0,00-0,20 $\mathrm{m}$ e 0,20- 0,40 $\mathrm{m}$, para avaliação dos atributos granulométricos, químicos e da suscetibilidade magnética do solo. Foram avaliados os atributos da cana-de-açúcar em 32 subáreas. A dependência espacial dos atributos foi estimada por meio do semivariograma, semivariograma escalonado e correlação dos mapas de distribuição espacial. Os resultados mostram que a suscetibilidade magnética apresentou um erro 33 a $50 \%$ menor do que a outros atributos físicos e químicos do solo na delimitação dos limites para áreas de manejo específico para cana-de-açúcar. Além disso, a suscetibilidade magnética teve correlação espacial significativa com os atributos físicos e químicos do solo e os atributos da cana-de-açúcar, podendo ser utilizada para auxiliar no mapeamento de áreas de manejo especifico para a cultura da cana-de-açúcar.

Palavras-chave: pedometria, análise multivariada, semivariograma escalonado e função de pedotransferência. 


\title{
MAGNETIC SUSCEPTIBILITY FOR THE SOIL ATTRIBUTES ESTIMATIMATION AND AREA MAPPING UNDER SUGAR CANE CULTIVATION
}

\begin{abstract}
The aim of this study was to evaluate the potential of magnetic susceptibility in estimating soil attributes and to map specific management areas under sugar cane cultivation. Two experiments were carried out. In the first, 50 points were sampled, at random, in an area of $2 \mathrm{ha}$, in 0.00 to $0.20 \mathrm{~m}$ depth. It has been constructed a calibration curve in order to convert the soil sample readings, taken from the balance, in magnetic susceptibility measurements. The magnetic susceptibility measured by an analytical balance had a 0.58 correlation with the clay content, -0.75 with the organic matter content, 0.41 to saturation and 0.82 with the hematite content in a soil depth from 0.00 to $0.20 \mathrm{~m}$. The multivariate statistical analysis of principal components show that the magnetic susceptibility explains $10.69 \%$ of the soil set properties variance. In the second experiment were taken (irregular grid) 110 samples, at random, in a 770 ha area in two different depths, one from 0.00 to $0.20 \mathrm{~m}$ and other from 0.20 to $0.40 \mathrm{~m}$, to assess the soil texture and chemical attributes and the magnetic susceptibility. The sugar cane attributes over 32 subareas were also evaluated. The spatial dependence in soil attributes was estimated through the semivariogram, scaled semivariogram and spatial distribution correlation maps. The results show that the magnetic susceptibility presented 33 to $50 \%$ error which is lower than the physical and chemical properties to define the specific management areas limits in sugar cane. In addition, the magnetic susceptibility had a significant spatial correlation with the sugar cane chemical and physical attributes and can be used to aid in the specific management areas mapping for sugar cane cultivation.
\end{abstract}

Keywords: pedometry, multivariate analysis, scaled semivariogram and pedotransfer function. 


\section{Capítulo 1. CONSIDERAÇÕES GERAIS}

\subsection{Introdução}

Ao longo de 30 anos, tem sido intenso o investimento brasileiro em pesquisas visando uma melhor elaboração e compreensão dos chamados ambientes de produção para a cultura da cana-de-açúcar. Trata-se de um espaço físico mapeado com base nas características edafoclimáticas para a expressão máxima do potencial genético da cultura (MAULE et al., 2001; LEPSCH, 1987). Uma das etapas da definição de um ambiente de produção é a caracterização dos atributos químicos e físicos utilizando o levantamento de solo. Os ambientes de Produção são elaborados com base nos levantamentos de solos (taxonômicos), e características agronômicas da cana-deaçúcar, por isso é considerada uma classificação técnica, com finalidade específica de uso, visando a locação de variedades e manejo da cana-de-açúcar.

No entanto, muitos dos levantamentos de solos, mesmo em escalas mais detalhadas (1: 5.000), não possuem controle da variabilidade espacial dos atributos do solo. No Brasil, os únicos levantamentos que registraram a variabilidades dos atributos são os realizados pelo IAC (1983) na escala de 1:20.000. Porém, ainda assim BERG \& OLIVEIRA (2000) julgam não ser suficiente para registrar a variabilidade dos atributos do solo. Em taxonomia de solo as classes são uma concepção teórica, que se enquadram dentro de certos limites estabelecidos pelo homem em laboratório e que não coincide necessariamente com representação da sua continuidade na paisagem.

Para resolver este problema alguns autores propõem o uso de modelos de classificação numérica para melhor identificação e mapeamento destes limites no campo (CUNHA et al. 2005; MINASNY \& McBRATNEY, 2007). Dentre os modelos de classificação numérica, destacam-se aqueles que fazem uso de técnicas para estudo da variabilidade espacial.

Assim, os levantamentos de solos com controle da variabilidade espacial dos atributos, ao ser utilizado para elaboração dos ambientes de produção, teriam poder de 
informação similar às zonas mínimas de manejo, ou áreas de manejo específico, conceitualmente utilizadas em agricultura de precisão.

GARRITY \& AGUSTIN (1995) e MARQUES JÚNIOR (2009) propõem que a avaliação e pesquisa de opções de manejo em áreas específicas envolvam a análise espacial quantitativa do solo, permitindo identificar seus potenciais e limitações. Nesse sentido, uma das sugestões é a identificação e mapeamento de áreas de manejo específico com base no estudo da variabilidade dos atributos do solo. Dentro de uma mesma área, a variabilidade dos atributos do solo é mínima, próximo a homogeneidade (MALLARINO et al., 2001; SIQUEIRA et al., 2010). Além disso, a identificação e delimitação das áreas de manejo específico permitem a transferência de tecnologia para áreas semelhantes.

Porém, estudos sobre a variabilidade espacial necessitam de grande número de amostras, o que implica a elevação do custo, tempo de coleta e realização das análises dos atributos do solo e impacto ambiental provocado pela utilização de reagentes. Segundo DEMATTÊ et al. (2007) a pouca aplicabilidade da agricultura de precisão na America do Sul é atribuída principalmente aos altos custos das análises de solos. A agricultura atual necessita de metodologias para determinação de atributos do solo que sejam menos agressivas ao meio ambiente, menos onerosas, e que auxiliem no mapeamento da variabilidade destes atributos com maiores níveis de detalhe. Estas premissas, também utilizadas pela agricultura de precisão, podem justificar o alto investimento no melhoramento genético das culturas agrícolas (MARQUES JÚNIOR et al., 2009).

Assim, um método alternativo para estimar atributos do solo é a suscetibilidade magnética (GRIMLEY \& VEPRASKAS, 2000). O mapeamento da suscetibilidade magnética vem se destacando como um dos métodos mais utilizados para fins ambientais (GRIMLEY et al., 2004). DEARING et al. (1996), ressaltam que a suscetibilidade magnética é ideal para a realização de estudos que requerem uma grande quantidade de amostras. Tão importante quanto o tamanho da amostra para representação de uma área, é a ferramenta estatística utilizada no estudo da continuidade espacial da relação solo-planta (MARQUES JR et al. 2009). Uma delas é o 
semivariograma escalonado (CEDDIA et al., 2009), capaz de representar simultaneamente vários padrões de distribuição espacial. Isto auxilia na compreensão da similaridade existente entre a variabilidade espacial de diferentes atributos. Outra ferramenta é a análise multivariada, que analisa de forma simultânea vários atributos do solo, fornecendo resultados mais consistentes e práticos (MINGOTI, 2005). Neste sentido o objetivo deste estudo foi avaliar o potencial da suscetibilidade magnética para estimar atributos do solo e mapear áreas de manejo especifico para a cultura da canade-açúcar.

\subsection{Revisão de Literatura}

\subsubsection{Levantamento de solos, variabilidade dos atributos do solo e áreas de manejo específico}

No extenso território brasileiro, por meio dos levantamentos de solos de pequena escala pode-se ter uma ampla visão de seus solos e reconhecer grandes áreas com relativa homogeneidade. Neste sentido, é de grande reconhecimento o trabalho desenvolvido por agências como a Embrapa e o Projeto Radambrasil, pela realização dos levantamentos de solos em extensas áreas do país.

Muitos destes mapas estão sendo úteis para apoiar estudos atuais que focalizam problemas que certamente não poderiam ter sido previstos. Porém, muitas áreas brasileiras mais intensamente utilizadas, necessitam de levantamentos em maior níveis de detalhe (detalhados e semidetalhados) do que os de reconhecimento e exploratórios (Tabela 1). Entretanto estes são escassos, sendo a principal causa dessa escassez a falta de recursos financeiros e de pedólogos especializados para o necessário, intenso e contínuo trabalho de campo, imprescindível para efetuar mapas mais detalhados (> 1:50.000). Destaque-se ainda a subjetividade implícita nestes métodos tradicionais de levantamento de solos, responsáveis por distorções nas unidades de mapeamento. Ademais, existe a falta de conhecimento humano sobre os fenômenos naturais que originam o comportamento aparentemente aleatório das variações pedogenéticas em 
diferentes escalas (WEBSTER, 2000), as quais dificultam ainda mais os estudos de causa-efeito, ou seja, da interação solo-planta.

Nos ambientes tropicais, segundo BUOL (1990), a realidade da variabilidade dos solos foi mascarada pelos levantamentos de reconhecimento em pequena escala (menos detalhados), que proporcionaram um falso sentido de uniformidade contribuindo, desta maneira, para ampliar a distância entre pesquisadores que interpretavam os mapas e os agricultores que queriam saber como era o solo que agricultavam.

Tabela 1. Diferenciação dos tipos de levantamentos (Modificado de EMBRAPA, 2006).

\begin{tabular}{|c|c|c|c|c|c|c|}
\hline \multirow{2}{*}{$\begin{array}{l}\text { Nível de } \\
\text { levantamento do } \\
\text { solo }\end{array}$} & \multirow{2}{*}{$\begin{array}{l}\text { Constituição da } \\
\text { unidade de } \\
\text { mapeamento }\end{array}$} & \multirow{2}{*}{$\begin{array}{l}\text { Escala } \\
\text { preferencial } \\
\text { dos mapas }\end{array}$} & \multirow[b]{2}{*}{$\begin{array}{c}\text { Inclusões } \\
(\%)\end{array}$} & \multirow{2}{*}{$\begin{array}{c}\text { Área } \\
\text { mínima } \\
\text { mapeável } \\
\text { (ha) }\end{array}$} & \multicolumn{2}{|c|}{ Número amostras ha ${ }^{-1}$} \\
\hline & & & & & $\begin{array}{c}\text { EMBRAPA } \\
(2006)\end{array}$ & $\begin{array}{c}\text { MCBRATNEY } \\
\text { et al. (2003) }\end{array}$ \\
\hline Exploratório & Ordem & $\begin{array}{l}1: 750.000 \text { à } \\
1: 2.500 .000\end{array}$ & & $\begin{array}{l}2.250 \mathrm{a} \\
25.000\end{array}$ & $<0,0004$ & $<0,0025$ \\
\hline Reconhecimento & $\begin{array}{l}\text { Grandes } \\
\text { grupos a } \\
\text { Subgrupos }\end{array}$ & $\begin{array}{l}1: 50.000 \text { à } \\
1: 750.000\end{array}$ & $\leq 30$ & 10 a 2.250 & $\begin{array}{c}0,0004 a \\
0,02\end{array}$ & 0,025 \\
\hline Semidetalhado & Famílias & $\geq 1: 50.000$ & $\leq 25$ & $<10$ & 0,02 a 0,2 & 4 \\
\hline Detalhado & $\begin{array}{l}\text { Famílias à } \\
\text { Série }\end{array}$ & $\geq 1: 20.000$ & $\leq 20$ & $<1,6$ & 0,2 a 4 & 25 \\
\hline Ultra detalhado & Série & $\geq 1: 5.000$ & $\leq 15$ & $<0,1$ & $>4$ & 400 \\
\hline
\end{tabular}

Extensas áreas do Estado de São Paulo, principalmente aquelas inseridas no domínio da Bacia do Paraná, tiveram os seus solos mapeados pela iniciativa governamental representados pelo programa de levantamento de solos do IAC. Em escalas maiores registram-se os levantamentos realizados pela iniciativa privada, em áreas de empresas agrícolas, para fins de aplicação tecnológica e gerenciamento da produção agrícola.

Entretanto, não muito raro são as manifestações de descontentamento dos agricultores em relação a pouca informação extraída dos levantamentos e inventários de terra, para o planejamento eficiente de suas atividades. Embora sejam unânimes em afirmar sobre a importância do solo na produção agrícola. A despeito deste antagonismo, ressalta-se a pequena habilidade do técnico do setor em adaptar e aplicar as informações contidas na carta de solos de maneira prática e objetiva. 
Em varias situações, a escala dos levantamentos representa a maior dificuldade para utilização das informações nele contidas, por apresentar, para grandes áreas, impressões de uniformidade da ocorrência dos solos. Isto causa a desconfiança do produtor rural, que por sua experiência, bem sabe da variabilidade da ocorrência dos solos em seus atributos, expresso pelo comportamento diferenciado das culturas.

Erroneamente, se pensa que, em algumas situações, a classificação do solo até o terceiro nível categórico (grande grupo) é suficiente para fazer o enquadramento das áreas agrícolas. Na unidade taxonômica pura (classe de solo definida e conceituada segundo parâmetros de classificação) é tolerado um erro de até $30 \%$ nos solos identificados (Tabela 1). Nos EUA, no nível de série dos mapas de solos, pode haver até $40 \%$ de erro nos solos identificados. Assim, nos mapeamentos que não contemplam a variabilidade dos atributos do solo em escalas mais detalhadas existe um equivoco quanto à uniformidade real (BUOL, 1990). Autores relatam que mapas com escala de 1:6.000 ou maior, são necessários para definir adequadamente a variabilidade espacial no campo (MAUSBACH et al., 1993).

Vários estudos indicaram que numa mesma unidade de mapeamento de solo existe considerável variabilidade espacial dos atributos (LIMA \& SILANS, 1999; MONTANARI et al., 2005; CAMARGO et al., 2008). Estes atributos do solo que interferem na produção e qualidade da cana-de-açúcar estão sendo constantemente estudados sob diferentes temas e escalas (Tabela 2).

Estudos sobre a variabilidade dos atributos do solo em diferentes escalas permitem explorar ao máximo o local de produção para promover o melhor rendimento da cultura e conseqüentemente maior lucratividade ou competitividade para a agroindústria da cana-de-açúcar (MAULE et al., 2001). MILLER et al. (1988) afirmaram que a variação dos atributos da planta acompanha a distribuição espacial e variação de nutrientes no solo. Segundo SALVIANO et al. (1998) isto ocorre porque a planta atua como integradora da variabilidade dos atributos do solo. 


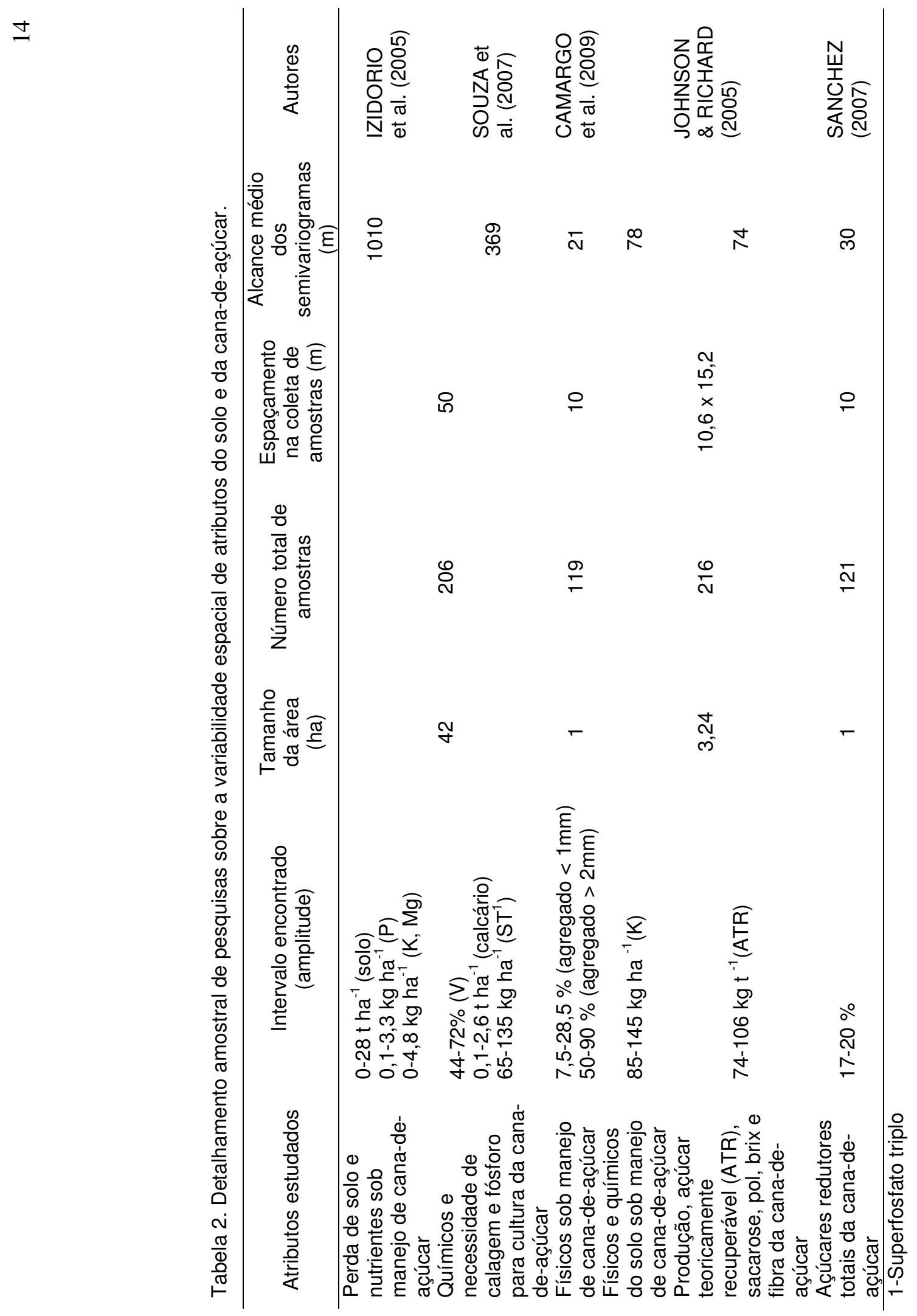


JOHNSON \& RICHARD (2005) estudando a variabilidade especial dos atributos do solo e da cana-de-açúcar em dois locais por 3 anos, relatam sobre a alta correlação espacial entre atributos do solo e da planta. Na maioria dos casos onde não é encontrada correlação espacial entre atributos do solo e da planta, o mapeamento dos atributos do solo feito em pequena escala são utilizados em planejamentos para culturas agrícolas que requerem compreensão da variabilidade em grande escala.

Os ambientes de produção para cana-de-açúcar assim como outras classificações técnicas, como o mapa de capacidade e uso do solo, são elaborados com base nos levantamentos de solos (taxonômico). Como mencionado anteriormente, estes levantamentos não levam em conta a variabilidade dos atributos do solo em escalas mais detalhadas. Assim, os levantamentos de solos com controle da variabilidade espacial dos atributos, ao ser utilizado para elaboração dos ambientes de produção, teriam poder de informação similar às zonas mínimas de manejo, ou áreas de manejo específico, conceitualmente utilizado em agricultura de precisão.

GARRITY \& AGUSTIN (1995) e MARQUES JÚNIOR (2009) propõem que os estudos sobre manejo do solo, envolvam a análise espacial quantitativa dos seus atributos, permitindo identificare mapear áreas de manejo específico. Neste local a variabilidade dos atributos do solo é mínima, próximo à homogeneidade, permitindo a transferência de tecnologia para áreas semelhantes (MALLARINO et al., 2001; SIQUEIRA et al. 2010).

Segundo McBRATNEY et al. (2003), uma das razões do pouco conhecimento sobre a variabilidade dos atributos do solo, é devido ao elevado custo e a demanda de tempo requerido para a realização dos levantamentos convencionais. Dessa maneira, são necessários métodos alternativos para quantificação dos atributos do solo (pedometria), que permitam aumentar o número de amostras coletadas sem que haja aumento de custo e tempo de análise. 


\subsubsection{Suscetibilidade magnética na determinação indireta de atributos do solo}

O Brasil possui grandes áreas com potencial para a expansão agrícola, mas nestes locais pouco se conhece sobre a variabilidade dos atributos do solo. Este conhecimento é indispensável para identificar o potencial agrícola, além de não garantir o desenvolvimento de forma sustentável das práticas de manejo do solo (LÓPEZ, 2009).

A coleta de amostras é a etapa mais intensiva e onerosa, na avaliação quantitativa dos atributos do solo para o planejamento agrícola (McBRATNEY et al., 2002). Atualmente, funções de pedotransferência tem sido desenvolvidas e utilizadas em ciência do solo para que diminuir o custo na obtenção da informação e compreender melhor o funcionamento dos processos do solo que interferem na resposta das culturas agrícolas.

As funções de pedotransferência (FP) podem ser definidas como modelos matemáticos utilizados para fazer estimativas de atributos dos solos a partir de outros atributos medidos com maior facilidade e baixo custo. Embora a maioria das FP tenha sido desenvolvida para estimar propriedades hidráulicas do solo, não se restringem a este fim. McBRATNEY et al. (2002) apresentam inúmeras FPs desenvolvidas para estimar atributos físicos, químicos e biológicos do solo.

A resistividade elétrica e condutividade eletromagnética são os métodos geofísicos mais utilizados como função de pedotransferência para mapear a variabilidade espacial dos atributos do solo de maneira indireta (JOHNSON et al., 2001; BRENNING et al., 2008). Porém, as medições feitas por estas técnicas sofrem variações em função do teor de água no solo.

Outro método alternativo para estimar atributos do solo é a suscetibilidade magnética (SM) (GRIMLEY \& VEPRASKAS, 2000). A SM é o grau de magnetização de um material em resposta a um campo magnético aplicado. É produzida por indução do campo magnético terrestre durante a cristalização do mineral presente na rocha ou no solo, e se origina das propriedades de rotação dos elétrons (CRAIK, 1995; LUQUE, 2008). 
São considerados 5 tipos básicos de comportamento magnético: diamagnetismo, paramagnetismo, ferromagnetismo, ferrimagnetismo e antiferromagnetismo (Figura 1). O mapeamento da SM vem se destacando como um dos métodos mais utilizados para fins ambientais (DEARING et al., 1996; GRIMLEY et al., 2004). Porém, segundo BECEGATO et al. (2005) pesquisas geofísicas em solos agrícolas ainda são muito insipientes no Brasil.
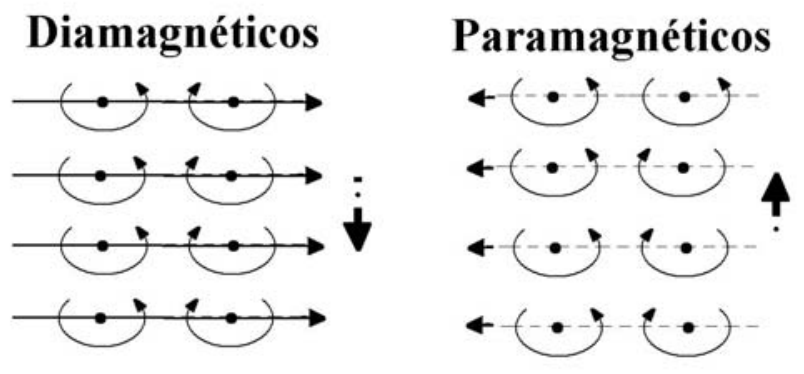

\section{Ferrimagnéticos}

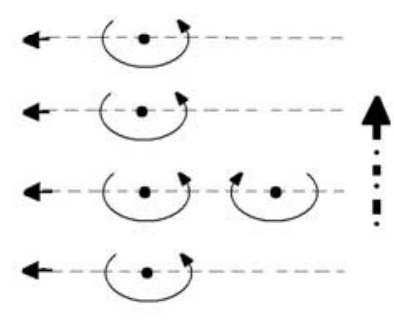

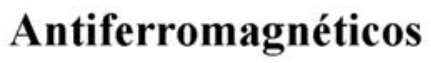

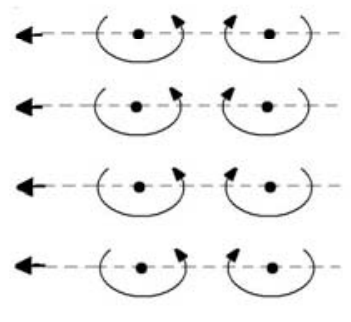

Ferromagnéticos
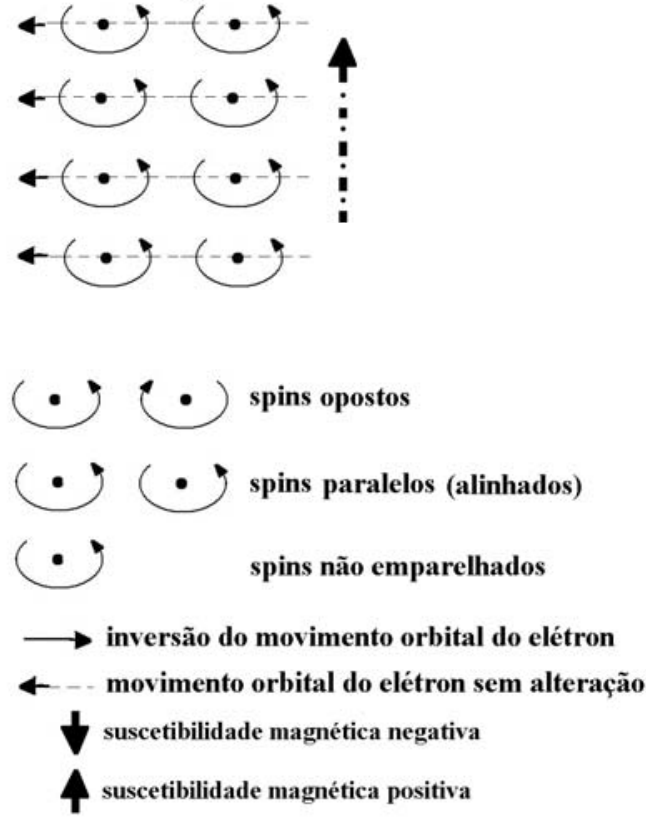

Figura 1. Tipos de comportamento magnético na presença de um campo magnético externo (imã).

Nos minerais diamagnéticos os átomos que compõem a cela unitária do mineral, possuem as camadas eletrônicas preenchidas. Assim, o número de spins eletrônicos alinhados numa direção é igual ao número de spins eletrônicos na direção oposta. $O$ campo magnético externo não exerce influência sobre os spins nesse caso, mas inverte o movimento orbital dos elétrons (Exemplo: quartzo). Nos minerais paramagnéticos as camadas eletrônicas estão incompletas. A presença de um campo magnético externo faz com que os spins se alinhem, e mesmo após a retirada do campo magnético, alguns spins permanecem alinhados (Exemplo: olivina). 
Os minerais ferromagnéticos são um caso especial de paramagnetismo. Após a retirada do campo magnético os spins permanecem alinhados, fazendo com que o mineral possua um grande valor de magnetização remanescente (Exemplo: ferro e cobalto). Nos minerais ferrimagnéticos os spins não estão emparelhados, assim prevalece o momento magnético do maior número de spins no mesmo sentido (Exemplo: magnetita). Os minerais antiferromagnéticos não apresentam propriedades magnéticas.

MATHÉ et al. (2006) mencionam que os minerais magnéticos podem ser considerados como micro-marcadores dos atributos do solo. As propriedades cristalográficas destes minerais refletem os fatores e processos de formação do solo (MAHER \& THOMPSON, 1999). Como esses fatores e processos são específicos para cada local, a suscetibilidade mostra-se uma promissora ferramenta no mapeamento destes locais, principalmente nos solos tropicais (Tabela 3). DEARING et al. (1996), ressaltam que a SM é ideal para a realização de estudos que requerem uma grande quantidade de amostras.

Tabela 3. Suscetibilidade magnética (SM) de diferentes tipos de solos (Modificado de RESENDE et al., 1988).

\begin{tabular}{|c|c|c|c|c|c|c|}
\hline \multirow[t]{2}{*}{ Solo } & \multirow{2}{*}{$\begin{array}{l}\text { Material de } \\
\text { origem }\end{array}$} & \multirow{2}{*}{$\begin{array}{l}\text { Cor úmida } \\
\text { Munsell }\end{array}$} & \multirow{2}{*}{$\begin{array}{c}\mathrm{Fe}_{2} \mathrm{O}_{3} \\
(\%)\end{array}$} & \multicolumn{3}{|c|}{$\begin{array}{l}\mathrm{SM}\left(10^{-6} \mathrm{~m}^{3} \mathrm{~kg}^{-1}\right) \\
\text { Frações do solo }\end{array}$} \\
\hline & & & & Areia & Silte & Argila \\
\hline 1 & Basalto & 4YR 4/4 & 30 & 144,6 & 25,5 & 10,46 \\
\hline 2 & $\begin{array}{c}\text { Arenito Grupo } \\
\text { Bauru }\end{array}$ & $1,5 \mathrm{YR} 3,5 / 6$ & 3,4 & 0,71 & 6,43 & 1,18 \\
\hline 3 & Basalto & $1 Y R 3 / 4$ & 29,6 & 191,46 & 166,52 & 53,17 \\
\hline 4 & Basalto & $1 Y R 3 / 5$ & 22,9 & 82,92 & 36,80 & 18,83 \\
\hline 5 & Basalto & $3,5 Y R 3,5 / 5$ & 23,1 & 45,25 & 22,22 & 4,58 \\
\hline 6 & Basalto & $5 Y R 3,5 / 5$ & 24 & 39,71 & 24,30 & 0,77 \\
\hline
\end{tabular}

1. Latossolo distrófico A moderado; 2. Latossolo A proeminente; 3. Nitossolo (Typic Acrorthox);

4. Nitossolo $A$ moderado (Typic Haplorthox); 5. Latossolo Vermelho álico A proeminente textura muito argilosa (Typic Acrohumox); 6. Latossolo Vermelho álico (Typic Acrohumox).

Vários trabalhos envolvendo a SM apresentaram resultados de correlação com atributos físicos e químicos dos solos (HANESCH \& SCHOLGER, 2005), atributos 
mineralógicos em diferentes classes de solos (CHEVRIER \& MATHÉ, 2007; TORRENT et al., 2007), e relação com atributos da cana-de-açúcar (MARQUES JR., 2009).

Os estudos que envolvem a SM (DEARING, 1999; PREETZ et al., 2008) utilizam sensores próprios para estes fins (Bartington Instruments, Witney, UK). Porém, outros autores apresentam métodos alternativos para determinação da SM, como o magnetômetro (FABRIS et al., 1998) e balança analítica (CARNEIRO et al., 2003; CANO et al., 2008). A vantagem dos métodos alternativos, principalmente o da balança analítica, é a flexibilidade. Mesmo com métodos adequados para avaliação da SM, o desenvolvimento de FP é uma tarefa difícil para aplicações em outros locais. Não se recomenda a utilização de FPs para além da região geomórfica, tipo de solo ou área de manejo específico, a partir da qual foi desenvolvida (McBRATNEY et al., 2002). Nesse sentido, são necessários estudos que possuam como objetivo investigar a correlação espacial da SM com atributos do solo em diferentes locais. Assim, os resultados são validados e a SM pode ser utilizada como FP pelo setor produtivo.

\subsubsection{Geoestatística: Semivariograma escalonado}

A variabilidade espacial dos atributos do solo é estudada desde o início do século XX (SMITH, 1910; MONTGOMERY, 1913). Essas mesmas técnicas: casualização, repetição, funções de distribuição, etc, são utilizadas até hoje. Em muitos locais o planejamento agrícola é feito com base em estatísticas como média e desvio padrão e não assumindo a interdependência entre as amostras. Porém, para que a interação existente entre solo e planta seja melhor compreendida, são precisos estudos em situações reais de campo, em áreas comerciais, ou invés de pequenas áreas experimentais, as quais muitas vezes não são validas ao longo da paisagem (STEVENSON et al., 2001).

Em 1951, na África do Sul o Engenheiro de Minas D. G. Krige, trabalhando com dados de concentração de ouro, concluiu que não conseguia encontrar sentido na variância caso não levasse em consideração à distância entre as amostras. MATHERON (1963), baseado nestas observações, desenvolveu a Teoria das Variáveis 
Regionalizadas. De acordo com TRANGMAR et al. (1985) uma variável aleatória é uma medida que varia de acordo com alguma lei de distribuição de probabilidade, sendo caracterizada pelos momentos da distribuição, tais como valor esperado e variância. Quando a variável aleatória assume diferentes valores em função da localização onde é amostrada no campo, caracteriza-se uma variável regionalizada, base da geoestatística.

Dentre as técnicas geoestatística, com as quais é possível estimar a dependência espacial, estão as medidas da autocorrelação e da semivariância. A partir dos gráficos destas medidas em função da distância, é possível modelar a dependência espacial (Figura 2).

a.

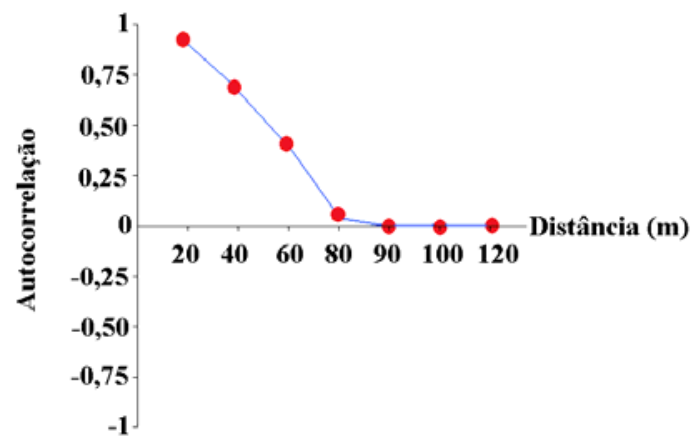

c. b.

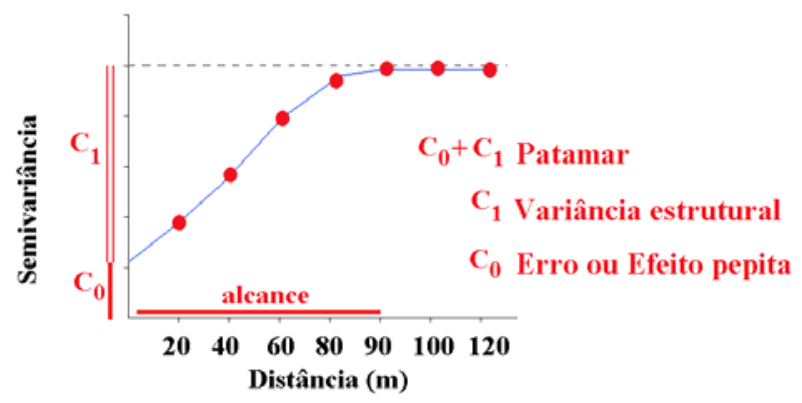

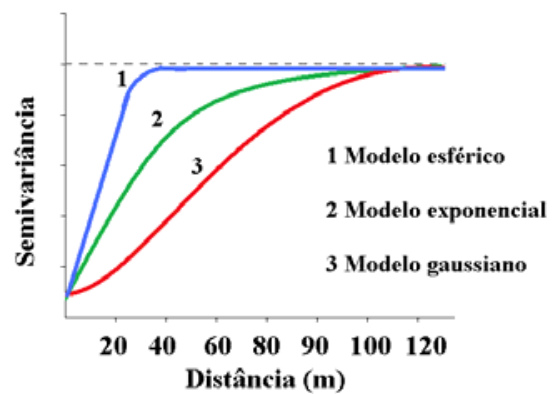

Figura 2. Autocorrelograma (a), semivariograma e seus parâmetros (b) e modelos de dependência espacial (c).

O semivariograma pode ser validado por várias técnicas, as mais usuais são: coeficiente de determinação $\left(r^{2}\right)$, validação cruzada (ISAAKS \& SRIVASTAVA, 1989) e Jack-Knifing (VIEIRA, 1995). Após modelar o semivariograma experimental, é possível estimar valores da variável em estudo em pontos não amostrados dentro da área por 
meio dos interpoladores. Existem alguns interpoladores, sendo que o mais complexo e utilizado é a krigagem. Segundo KRAVCHENCO \& BULLOCK (1999), a krigagem foi o melhor interpolador para parâmetros da paisagem entre os métodos por eles analisados. Esta técnica de interpolação recebeu este nome em homenagem Daniel G. Krige. Consiste em uma média ponderada dos vizinhos que estão dentro da influência da dependência espacial (a - alcance) capturada na modelagem do semivariograma (VIEIRA et al., 1981) (Figura 3).
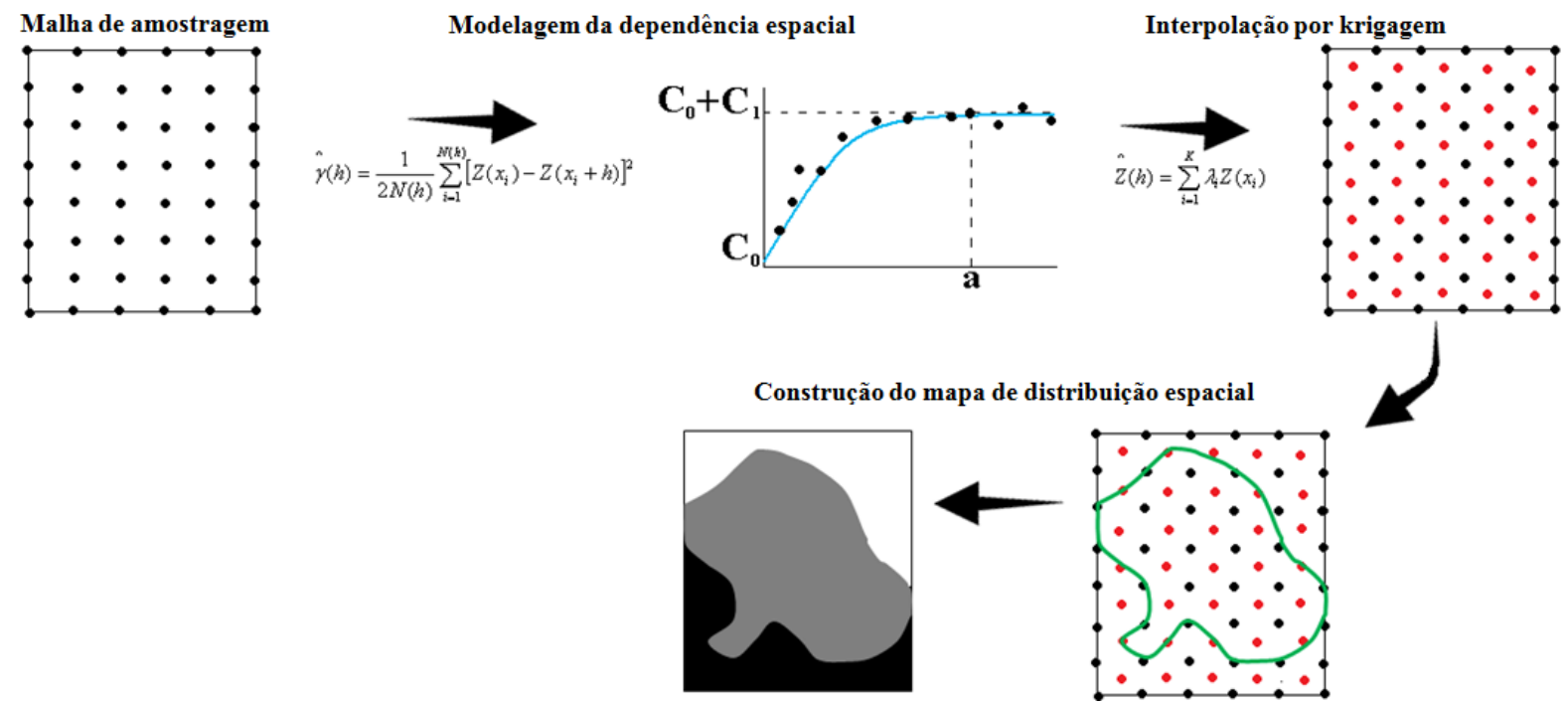

Figura 3. Etapas na modelagem da variabilidade espacial utilizando a krigagem como interpolador.

Dessa maneira, o uso da geoestatística no estudo da distribuição espacial de variáveis ao longo da paisagem, possibilita uma nova interpretação da interação entre atributos do solo e atributos das culturas. Esta técnica ampara decisões estratégicas e complexas em relação ao sistema de manejo adotado (PANOSSO et al., 2008), efeitos ambientais (LA SCALA JÚNIOR et al., 2000; IZIDORIO et al., 2005), otimização amostral (MONTANARI et al., 2005) e produtividade das diferentes culturas (LEÃO 2004; SOUZA 2004; SANCHEZ, 2009). Porém, nesses estudos, é necessária a modelagem individual da dependência espacial de cada atributo amostrado, para posteriormente relacionar as causas comuns da variabilidade. Isso faz com que seja 
criado um grande número de semavariograma, o que diminui a eficiência das praticas de planejamento que utilizam esta técnica.

Nesse sentido, alguns autores propõem a utilização do semivariograma escalonado. O objetivo é que vários semivariogramas sejam representados simultaneamente para compreender melhor as causas da variabilidade espacial (CEDDIA et al., 2009). Segundo VIERIA et al. (1997) o semivariograma escalonado é obtido pela relação entre a semivariância original e o número de atributos estudados Assim, análise da variabilidade espacial pelo semivariograma escalonado, auxilia na melhor representação da unidade amostral (COMEGNA \& BASILE, 1994; FERREYRA et al., 2002), economizando tempo e dinheiro.

\subsubsection{Análise multivariada na área de ciências agrárias}

A caracterização de uma área ou explicação de um fenômeno envolve a coleta e análise de diversas variáveis. Os objetivos podem ser vários: construir algum índice especifico relativo à quantificação dessa área ou fenômeno, dividir as variáveis em grupos, investigar a relação entre as variáveis medidas, etc. Porém, todos estes objetivos convergem para um objetivo em comum, o de validar hipóteses.

A gestão da atividade agrícola é feita com base em resultados quantitativos de inúmeros atributos do solo, da planta e do clima. O planejamento atual desta atividade é bastante complexo, pois deve atender requisitos de uma produção sustentável, a baixo custo e com máximo desempenho. As análises estatísticas convencionais muitas vezes não são suficientes para descrever as interações nesse sistema. Um das soluções propostas é a utilização da estatística multivariada por possuir maior capacidade de descrever as relações de inter e intradependência nos sistemas agrícolas (SIQUEIRA et al., 2010; MARQUES JR., 2009).

Os métodos de estatística multivariada são utilizados com o propósito de simplificar ou facilitar a interpretação de um fenômeno, por meio da análise simultânea de todas as variáveis medidas (KHATTREE \& NAIK, 2000; JOHNSON \& WICHERN, 2002). Historicamente, o método multivariado está relacionado com trabalhos na 
Psicologia, Ciências Sociais e Biológicas, porém recentemente tem sido aplicado em diferentes áreas, dentre elas a Ciências Agrárias. Esta expansão foi possível graças ao avanço da tecnologia computacional e ao número de softwares estatísticos (MINGOTI, 2005; FERREIRA, 2008).

A análise multivariada divide-se em dois grupos: - Técnicas exploratórias de simplificação das quais fazem parte a análise de componentes principais (ACP), análise fatorial, análise de correlações canônicas (ACC), análise de agrupamentos ou cluster, análise discriminante e análise de correspondência; - Técnicas de inferência estatística compostas pelos métodos de estimação de parâmetros, testes de hipóteses e análise de variância, covariância e regressão multivariada.

Dentre estas técnicas, a ACP é uma das mais utilizadas pela ciência do solo. O objetivo da ACP é encontrar em um conjunto de dados um atributo que seja capaz de explicar parte significativa da variância de toda população amostrada, por meio de correlações lineares (Figura 4). Esse tipo de análise é interessante para a ciência do solo porque pode eleger as variáveis mais significativas nos processos pedogenéticos (THEOCHAROPOULOS et al., 1997).

a.

Variável B

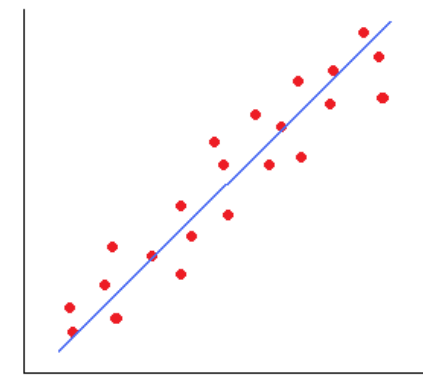

b.

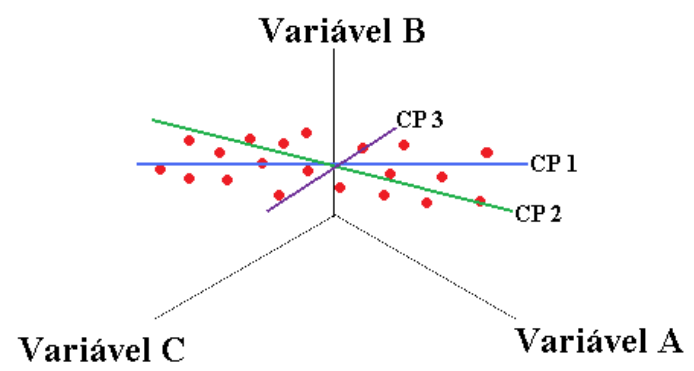

Variável A

Figura 4. Correlação linear simples (a) e análise de componentes principais (b) (Modificado de ESBENSEN et al. 2006).

Como exemplo de uso da ACP em ciência do solo pode-se citar os estudos com padrões regionais de diferenciação de solos na Amazônia colombiana (LIPS \& DUIVENVOORDEN, 1996), regime de nutrientes em diferentes solos florestais de uma 
costa montanhosa do Canadá (SPLECHTNA \& KLINKA, 2001), relações entre propriedades abióticas e bióticas do solo durante períodos de pousio no Senegal (MANLAY et al., 2000), ocorrência da macaúba em Minas Gerais, relacionada com atributos climáticos, pedológicos e vegetacionais (MOTTA et al., 2002), relação entre atributos físicos, químicos e mineralógicos de solos do bioma cerrado (GOMES et al., 2004) e a relação entre atributos físicos, químicos e suscetibilidade magnética do solo com atributos da cana-de-açúcar (MARQUES JR., 2009).

\subsection{REFERÊNCIAS}

BECEGATO, V. A.; FERREIRA, F. J. F. Gamaespectrometria, resistividade elétrica e suscetibilidade magnética de solos agrícolas no noroeste do Estado do Paraná. Revista Brasileira de Geofísica, São Paulo, v. 23, n. 4, p. 371-405, 2005.

BERG, M. van den; OLIVEIRA, J.B. Variability of apparently homogeneous soilscapes in São Paulo State, Brazil: I. Spatial Analysis. Revista Brasileira de Ciência do Solo, v.24, p.377-391, 2000.

BRENNING, A.; KOSZINSKI, S.; SOMMER, M., Geostatistical homogenization of soil conductivity across field boundaries. Geoderma, Amsterdam, v. 143, n. 3-4, p. 254-260, 2008.

BUOL, S. W. Suelos tropicales: classificación y características. In: SALINAS, J. G.; GOULEY, L. M. Sorgo para suelos ácidos. Cali: CIAT, 1990. p. 49-62.

BUOL, S. W. Suelos tropicales: classificación y características. In: SALINAS, J.G.; GOULEY, L.M. Sorgo para suelos ácidos, Cali, p.49-62, 1990. 
CAMARGO, L.A., MARQUES JR., J., PEREIRA, G.T., HORVAT, R.A. Variabilidade espacial de atributos mineralógicos de um latossolo sob diferentes formas do relevo: II correlação espacial entre mineralogia e agregados. Revista Brasileira de Ciência do Solo, Viçosa, v.32, p.2279-2288, 2008.

CANO, M.E., CORDOVA-FRAGA, T., SOSA, M., BERNAL-ALVARADO, J., BAFFA, O. Understanding the magnetic susceptibility measurements by using an analytical scale. European Journal Of Physics,v. 29,p.345-354, 2008.

CARNEIRO, A. A. O., TOUSO, A. T., BAFFA, O. Avaliação da suscetibilidade magnética usando uma balança analítica. Química Nova, v. 26, n. 6, p952-956, 2003.

CEDDIA, M. B.; VIEIRA, S. R.; VILLELA, A. L. O.; MOTA, L. S.; ANJOS, L. H. C.; CARVALHO, D. F. Topography and spatial variability of soil physical properties, Scientia Agrícola, Piracicaba, v.66, n.3, p. 338-352, 2009.

CHEVRIER V.; MATHÉ P. E. Mineralogy and evolution of the surface of Mars: a review. Planetary and Space Science, Elmsford, v. 55, n. 3, p. 289-314, 2007.

COMEGNA, V., BASILE, A. Temporal stability of spatial patterns of soil water storage in a cultivated Vesubian soil, Geoderma, Amsterdam, v.62, p.299-310, 1994.

CRAIK, D. Magnetism, Principles and Applications, John Wiley and Sons, p. 1-459. 1995.

CUNHA, P.; MARQUES JR. J, JOSÉ; C., NILTON; PEREIRA, G. T.; LEPSCH, I. F.. Superfícies geomórficas e atributos de Latossolos em uma seqüência AreníticoBasáltica da região de Jaboticabal (SP). Revista Brasileira de Ciência do Solo, v.29, n.1, p. 81-90, 2005. 
DEARING, J.A. Environmental magnetic susceptibility: Using the Bartington MS2 system. 2nd ed. Chi Publ., Kenilworth, UK, 1999.

DEARING, J.A., HAY, K.L., BABAN, S.M.K., HUDDLESTON, A.S., WELLINGTON, E.M. H., LOVELAND, P.J. Magnetic susceptibility of soil: an evaluation of conicting theories using a national data set. Geophysical Journal International, v.127, p.728-734, 1996.

DEMATTÊ, J. A. M., GALDOS, M. V., GUIMARÃES, R., GENÚ, A.M.; NANNI, M.R., ZULLO, JR., J. Quantification of tropical soil attributes from ETM+/Landsat-7 data. International Journal of Remote Sensing, London, v.8, p.3813-3829, 2007.

EMBRAPA. Centro Nacional de Pesquisa de Solos. Sistema brasileiro de classificação de solos.2. ed. Rio de Janeiro, 2006. p. 306.

ESBENSEN, K. H., GUYOT, D., WESTAD, F., HOUMOLLER, L. P. Multivariate Data Analysis - In Practice: An Introduction to Multivariate Data Analysis and Experimental Desing. 2006.

FABRIS, J.D., COEY, J.M.D., MUSSEL, W.N. Magnetic soils from mafic lithodomains in Brazil. Hyperfine Interactions, v.113, p. 249-258, 1998.

FERREIRA, D. F. Estatística multivariada. 1. ed., Lavras: Editora UFLA, 2008. 662 p.

FERREYRA, R. A., APEZTEGUÍA, H. P., SERENO, R., JONES, J.W. Reduction of soil water spatial sampling density using scaled semivariograms and simulated annealing. Geoderma, Amsterdam, v.110, p. 265-289, 2002.

GARRITY, D.P.; AGUSTIN, P.C. Historical land use evolution in a tropical acid upland agroecosystem Agriculture, Ecosystems and Environment, Amsterdam, v.53, n.1, p.8395, 1995. 
GOMES, J. B. V.; CURI, N.; MOTTA, P. E. F.; KER, J. C.; MARQUES, J. J. G. S. M.; SCHULZE, D. G. Análise de componentes principais de atributos físicos, químicos e mineralógicos de solos do bioma cerrado. Revista Brasileira de Ciência do Solo, Viçosa, v. 28, n. 1, p. 137-153, 2004.

GRIMLEY, D.A., ARRUDA, N.K., BRAMSTEDT, M.W. Using magnetic susceptibility to facilitate more rapid, reproducible, and precise delineation of hydric soils in the midwestern USA. Catena, Amsterdam, v.58, p.183-213, 2004.

GRIMLEY, D.A., VEPRASKAS, M.J. Magnetic Susceptibility for Use in Delineating Hydric Soils. Soil Science Society of America Journal, Madison, v.64, p.2174-2180, 2000.

GRUNWALD, S., ROONEY, D.J., McSWEENEY, K., LOWERY, B. Development of pedotransfer functions for a profile cone penetrometer. Geoderma, Amsterdam, v.100, p.25-47, 2001.

HANESCH, M., SCHOLGER, R. The influence of soil type on the magnetic susceptibility measured throughout soil profiles. Geophysical Journal International, v.161, p.50-56, 2005.

INSTITUTO AGRONOMICO DE CAMPINAS - IAC. Boletim técnico do IAC, n.76, p.1-30. 1983.

ISAAKS, E. H.; SRIVASTAVA, R. M. An introduction to applied geoestatistics. New York: Oxford University Press, 1989. p. 561. 
IZIDORIO, R.; MARTINS FILHO, M. V.; MARQUES JR., J.; SOUZA, Z. M.; PEREIRA, G.T. Perdas de nutrientes por erosão e sua distribuição espacial em área sob cana-deaçúcar. Engenharia Agrícola, Jaboticabal, v. 25, n. 3, p. 660-670, 2005.

JOHNSON, C.K., DORAN, J.W., DUKE, H.R., WIENHOLD, B.J., ESKRIDGE, K.M., SHANAHAN, J.F. Field-scale electrical conductivity mapping for delineating soil condition. Soil Science Society of America Journal, Madison, v. 65, p. 1829-1837, 2001.

JOHNSON, R. A.; WICHERN, D. W. Applied multivariate statistical analysis, 5. ed. Upper Saddle River: Prentice Hall, 2002.

JOHNSON, R. M., RICHARD, E. P. JR. Sugarcane Yield, Sugarcane Quality, and Soil Variability in Louisiana. Agronomy Journal, v.97, p.760-771, 2005.

KHATTREE, R.; NAIK, D. N. Multivariate data reduction and discrimination with SAS Software. Cary: SAS Institute, 2000.

KRAVCHENKO, A. N.; BULLOCK, D.G. Comparative study of interpolation methods for mapping soil properties. Agronomy Journal, Madison, v. 91, n. 3, p. 393-400, 1999.

LA SCALA JÚNIOR, N.; MARQUES JR., J.; PEREIRA G. T.; CORÁ J. E. Short-term temporal changes in the spatial variability model of $\mathrm{CO} 2$ emissions from a Brazilian bare soil. Soil Biology \& Biochemistry, Exeter, v. 32, n. 10, p. 1459-1462, 2000.

LAGACHERIE, P., McBRATNEY, A.B. Spatial soil information systems and spatial soil inference systems: perspectives for digital soil mapping. In: LAGACHERIE, P.; McBRATNEY, A.B.; VOLTZ, M. (Ed.). Developments in soil science, Amsterdam: Elsevier, 2006. v. 31, p. 1- 15. (Digital Soil Mapping: An Introductory Perspective, 31). 
LEÃO, M. G. A. Relação entre atributos de uma vertente com Latossolos e qualidade de frutos cítricos. 2004. 119 f. Dissertação (Mestrado em Ciência do Solo) - Faculdade de Ciências Agrárias e Veterinárias, Universidade Estadual Paulista, Jaboticabal, 2004.

LEPSCH, I.F. Influência dos fatores edáficos na produção. In: CASTRO, P.R.C.; FERREIRA, S.O.; YAMADA, T. (Coord.) Ecofisiologia da produção. Piracicaba: Associação Brasileira para Pesquisa da Potassa e do Fosfato, 1987. p.83-98.

LIMA, C. A. G.; SILANS, A. P. Variabilidade espacial da infiltração de água no solo. Pesquisa Agropecuária Brasileira, Brasília, v. 34, n. 12, p. 2311-2320, 1999.

LIPS, J.M., DUIVENVOORDEN, J.F. Regional patterns of well drained upland soil differentiation in the middle Caquetá basin of Colombian Amazonia. Geoderma, v. 72, p.219- 257, 1996.

LÓPEZ, L. R. Pedologia quantitativa: espectrometria VIS-NIR-SWIR e mapeamento digital de solos. 2009. 171 f. Dissertação (Mestrado em Solos e Nutrição de Plantas) Escola Superior de Agricultura Luiz de Queiroz (ESALQ), Piracicaba 2009.

LUQUE, E. C. L. Propiedades magnéticas de los óxidos de hierro en suelos mediterráneos. 2008. 179 f. Tese de doutorado - Escuela Técnica Superior de Ingenieros Agrónomos y de Montes, Universidad de Córdoba, Córdoba, 2008.

MAHER, B.A., THOMPSON, R. The magnetic record of palaeoclimate in the terrestrial loess and palaeosol sequences, in Quaternary Climates. In: Environments and Magnetism (eds Maher, BA \& Thompson, R). University Press, Cambridge, pp. 81-125, 1999. 
MALLARINO, A. P.; MAZHAR. U. H.; WITTRY, D.; BERMUDEZ, M. Variation in Soybean Response to Early Season Foliar Fertilization among and within Fields, Agronomy Journal, Madison, v. 93, n. 6, p.1220-1226, 2001.

MANLAY, R.J.; CADET, P.; THIOULOUSE, J. \& CHOTTE, J. Relationships between abiotic and biotic soil properties during fallow periods in the sudanian zone of Senegal. Applied Soil Ecology, Amsterdam, v. 14, n. 2, p.89-101, 2000.

MARQUES JR, J. Caracterização de áreas de manejo específico no contexto das relações solo-relevo. 2009. 113 f. Tese (Livre-Docência) - Faculdade de Ciências Agrárias e Veterinárias, Universidade Estadual Paulista, Jaboticabal, 2009.

MATHÉ, V.; LÉVÊQUE, F.; MATHÉ, P. E.; CHEVALLIER, C.; PONS, Y. Soil anomaly mapping using a caesium magnetometer: Limits in the low magnetic amplitude case. Journal of Applied Geophysics, Amsterdam, v. 58, n. 3, p. 202-217, 2006.

MATHERON, G., Principles of geostatistics. Economic Geology, Littleton, v. 58, n. 8, p. 1246-1266, 1963.

MAULE, R. F., MAZZA, J. A., MARTHA JR., G. B. Produtividade agrícola de cultivares de cana-de-açúcar em diferentes solos e épocas de colheita. Scientia. Agrícola, Piracicaba, v. 58, p.295-301, 2001.

MAUSBACH, M. J., LYTLE, D. J., SPIVEY, L. D. Application of soil survey information to soil specific farming. In: ROBERT, P.C. et al. (eds.) Proc. of soil especific crop management: A workshop on research and development issues. SSSA Spec. Publ. Soil Sci. Soc. Am., Madison, p.57-68, 1993.

McBRATNEY, A. B.; SANTOS, M. L. M.; MINASNY, B. On digital soil mapping. Geoderma, Amsterdam, v. 117, n. 1-2, p. 3-52, 2003. 
McBRATNEY, A. B.; SANTOS, M. L. M.; MINASNY, B. On digital soil mapping. Geoderma, Amsterdam, v. 117, n. 1-2, p. 3-52, 2003.

McBRATNEY, A.; MYNASNY, B.; STEPHEN R. CATTLE, R. WILLEM VERVOORT. From pedotransfer functions to soil inference systems. Geoderma, Amsterdam. v. 109, p. 41-73. 2002.

McBRATNEY, A.B., MINASNY, B., CATTLE, S.R., VERVOORT, R.W. From pedotranfer functions to soil inference systems. Geoderma, Amsterdam, v.109, p.41-73, 2002.

McBRATNEY, A.B., MINASNY, B., VISCARRA ROSSEL, R.A. Spectral soil analysis and inference systems: A powerful combination for solving the soil data crisis. Geoderma, Amsterdam, v.136, p. 272-278, 2006.

MILLER, M. P.; SINGER, M. J.; NIELSEN, D. R. Spatial variability of weat yield and soil properties on complex hills. Soil Science Society of America Journal, Madison, v. 52, n. 5, p. 1133-1141, 1988.

MILTON C. C. C., MARQUES JR. J.,T. PEREIRA, G. T., SOUZA, Z. M. S., MONTANARI, R. Planejamento agrícola e implantação de sistema de cultivo de canade-açúcar com auxílio de técnicas geoestatísticas. Revista Brasileira de Engenharia Agrícola, vol.13, n.3, pp. 297-304, 2009.

MINASNY,B.; McBRATNEY, A. B. Incorporating taxonomic distance into spatial prediction and digital mapping of soil classes.Geoderma, v. 142, p. 285-293, 2007.

MINGOTI, S. A. Análise de dados através de métodos de estatística multivariada: uma abordagem aplicada. Belo Horizonte, Minas Gerais, 2005. 
MONTANARI, R.; MARQUES JÚNIOR, J.; PEREIRA, G. T.; SOUZA, Z. M. Forma da paisagem como critério para otimização amostral de latossolos sob cultivo de cana-deaçúcar. Pesquisa Agropecuária Brasileira, Brasília, v. 40 n. 1, p. 69-77, 2005.

MONTGOMERY, D. R. Predicting landscapescale erosion rates using digital elevation models. Comptes Rendus Geoscience, Paris, v. 335, n. 16, p. 1121-1130, 2003.

MOTTA, P. E. F.; CURI, N.; OLIVEIRA-FILHO, A. T. \& GOMES, J. B. V. Ocorrência de macaúba em Minas Gerais: relação com atributos climáticos, pedológicos e vegetacionais. Pesquisa Agropecuária Brasileira, v. 37, n. 7, p. 1023-1031, 2002.

PANOSSO, A. R., PEREIRA, G. T., MARQUES JR., SCALA, N. JR. Variabilidade espacial da emissão de $\mathrm{CO}_{2}$ em latossolos sob cultivo de cana-de-açúcar em diferentes sistemas de manejo. Engenharia Agrícola, v.28, p.227-236, 2008.

PREETZ, H., ALTFELDER, S., IGEL, J. Tropical Soils and Landmine Detection-An Approach for a Classifi cation System. Soil Science Society of America Journal, Amsterdam, v.72, p.151-159, 2008.

REZENDE, M.; SANTANA, D. P.; RESENDE, S. B. Suscetibilidade magnética em Latossolos do sudeste e Sul do Brasil. In: Anais da $3^{\circ}$ Reunião de Classificação, Correlação de Solos e Interpretações de Aptidão Agrícola. Rio de Janeiro, EMBRAPASNLCS/SECS, 1988, cap. 3, p. 233-258.

SANCHEZ, M. G. B. Relação solo relevo em áreas sob cultivo de café no sudoeste de Minas. 2009.90 f. Dissertação (Mestrado em Ciência do Solo) - Faculdade de Ciências Agrárias e Veterinárias, Universidade Estadual Paulista, Jaboticabal, 2009.

SANCHEZ, R. B. Agricultura de Precisão em Argissolos com variação nas formas de relevo sob o cultivo de cana-de-açúcar. 2007.101 f. Tese (Doutorado em produção 
vegetal)- Faculdade de Ciências Agrárias e Veterinárias, Universidade Estadual Paulista, Jaboticabal 2007.

SIQUEIRA, D.S., MARQUES JR., J., PEREIRA, G.T. The use of landforms to predict the variability of soil and orange attributes. Geoderma v. 155, 55-66, 2010.

SOUZA, Z. M.; BARBIERI, D. M.; MARQUES JUNIOR, J.; PEREIRA, G. T.; CAMPOS, M. C. C. Influência da variabilidade espacial de atributos químicos de um Latossolo na aplicação de insumos para cultura de cana-de-açúcar. Ciência. Agrotecnologia, Lavras, v. 31, n. 2, p. 371-377, 2007.

SOUZA, Z. M.; MARQUES JUNIOR, J.; PEREIRA, G. T.; MOREIRA, L. F. Variabilidade espacial do $\mathrm{pH}, \mathrm{Ca}, \mathrm{Mg}$ e $\mathrm{V} \%$ do solo em diferentes formas do relevo sob cultivo de cana-de-açúcar.Ciência Rural, Santa Maria, v. 34, n. 6, p. 1763-1771, 2004.

SPLECHTNA, B. E.; KLINKA, K. Quantitative characterization of nutrient regimes of high-elevation forest soils in the southern coastal region of British Columbia, Canada. Geoderma, v. 102, p. 153-174, 2001.

STEVENSON, F. C., KNIGHT, J. D., WENDROTH, O., KESSEL, C. VAN., NIELSEN, D. R. A comparison of two methods to predict the landscape-scale variation of crop yield. Soil and Tillage Research, v 58, p.163-181, 2001.

THEOCHAROPOULOS, S. P.; PETRAKIS, P. V.; TRIKATSOULA, A. Multivariate analysis of soil grid data as a soil classification and mapping tool: the case study of a homogeneous plain in Vagia, Viotia, Greece. Geoderma, Amsterdam, v. 77, n. 1, p. 6379, 1997. 
TORRENT, J., LIU, Q., BLOEMENDAL, J., BARRÓN, V. Magnetic enhancement and iron oxides in the upper Luochuan loess-paleosol sequence, Chinese Loess Plateau. Soil Science Society American Journal, Madison,v.71, p.1-9, 2007.

VIEIRA, S. R.; NIELSEN, D. R.; BIGGAR, J. W. Spatial variability of field - measured infiltration rate. Soil Science Society of America Journal, Madison, v. 45, n. 6, p.10401048, 1981.

VIEIRA, S.R.; LOMBARDI NETO, F. Variabilidade espacial do potencial de erosão das chuvas do Estado de São Paulo. Bragantia, Campinas, v. 54, n. 2, p. 405-412, 1995.

WEBSTER, R. Is soil variation random? Geoderma. v.97, p.149- 163, 2000.

WÖSTEN, J.H.M., PACHEPSKY, Y.A., RAWLS, W.J. Pedotransfer functions: Bridgin Reynoldsg the gap between available basic soil data and missing soil hydraulic characteristics. Journal of Hydrology, Amsterdam, v.251, p.123-150, 2001. 


\section{CAPÍTULO 2. ESTIMATIVA DOS ATRIBUTOS DO SOLO UTILIZANDO A SUSCETIBILIDADE MAGNÉTICA}

RESUMO - A suscetibilidade magnética é uma medida que tem sido utilizada nas medidas indiretas de atributos do solo com maior facilidade e baixo custo. $O$ objetivo do trabalho foi avaliar o potencial da suscetibilidade magnética para estimar atributos do solo. A área se localizada no município de Catanduva - SP e o solo foi classificado como Argissolo Vermelho-Amarelo eutrófico. Foram amostrados 50 pontos de forma aleatória em uma área de $2 \mathrm{ha}$, na profundidade de 0,00-0,20 $\mathrm{m}$. Na área, o teor médio de ferro total $\left(\mathrm{Fe}_{2} \mathrm{O}_{3}\right)$, na profundidade de $0,00-0,20 \mathrm{~m}$, é de $18 \mathrm{~g} \mathrm{~kg}^{-1}$. Foi construída uma curva de calibração para converter as leituras das amostras de solo feitas na balança em medidas de suscetibilidade magnética. A suscetibilidade magnética medida por uma balança analítica teve uma correlação de $0,58 \mathrm{com}$ o teor de argila, $-0,75$ com o teor de matéria orgânica, 0,41 com a saturação por bases e 0,82 com o teor de hematita do solo na profundidade $0,00-0,20 \mathrm{~m}$. A análise estatística multivariada dos componentes principais mostrou que a suscetibilidade magnética explica $10,69 \%$ da variância do conjunto de atributos do solo estudados. Isso mostra a possibilidade de uso da suscetibilidade magnética como função de pedotranferência para estimar outros atributos do solo.

Palavras-chave: função de pedotransferência, pedometria, mineralogia, análise multivariada. 


\subsection{INTRODUÇÃO}

As funções de pedotranferência são cada vez mais utilizadas na agricultura moderna para estimar atributos do solo de maneira simples e rápida. Segundo McBRATNEY et al. (2002) funções de pedotransferência podem ser definidas como modelos matemáticos utilizados para estimar atributos do solo a partir de outros atributos medidos com maior facilidade e baixo custo.

O mapeamento da variabilidade dos atributos do solo é fundamental para o planejamento sustentável das praticas agrícolas (FROGBROOK \& OLIVER, 2007). Porém, as técnicas estatísticas espaciais utilizadas nestes mapeamentos requerem elevado número de amostras. Isso aumenta o tempo necessário para construção dos mapas, eleva os custos, além de provocar maior impacto ambiental, devido ao uso de reagentes utilizados nas análises laboratoriais.

Métodos baseados na caracterização eletromagnética do solo, como a resistividade elétrica e condutividade eletromagnética, são os métodos geofísicos mais utilizados como função de pedotransferência para mapear a variabilidade espacial dos atributos do solo de maneira indireta (JOHNSON et al., 2001; BRENNING et al. 2008). Porém, as medições feitas por estas técnicas sofrem variações em função do teor de água no solo.

Outro método alternativo para estimar atributos do solo é a suscetibilidade magnética (GRIMLEY \& VEPRASKAS, 2000). Trata-se de uma característica dos minerais presentes nas rochas e no solo, cuja magnitude depende da concentração e características dos minerais, tais como composição, estrutura espacial do cristal e tamanho (VEROSUB \& ROBERTS, 1995). O mapeamento de suscetibilidade magnética vem se destacando como um dos métodos mais utilizados para fins ambientais (DEARING et al., 1996; GRIMLEY et al., 2004). DEARING et al. (1996), ressaltam que a suscetibilidade magnética é ideal para a realização de estudos que requerem uma grande quantidade de amostras.

MATHÉ et al. (2006) mencionam que os minerais magnéticos podem ser considerados como micro-marcadores dos atributos do solo. Segundo MAHER \& 
THOMPSON (1999) os minerais com capacidade magnética armazenam arquivos naturais contendo registros dos fatores e processos de formação do solo. Como esses fatores e processos são específicos para cada local, a suscetibilidade mostra-se uma promissora ferramenta no mapeamento destes locais, principalmente nos solos da Zona Tropical. Nesta região os óxidos de ferro respondem pela magnetização do solo, especificamente os ferrimagneticamente ordenados, como magnetita e maghemita (SILVA et al., 2005). Estes minerais são característicos de rochas de origem basáltica ou rochas sedimentares que tem o basalto com um de seus materiais formadores.

CHEVRIER \& MATHÉ (2007) comparando a suscetibilidade magnética dos solos de marte com os solos da Terra mostraram a forte influencia dos minerais na suscetibilidade magnética. HANESCH \& SCHOLGER (2005) encontraram correlações significativas entre os atributos físicos e químicos de diferentes tipos de solo e a suscetibilidade magnética.

A maioria dos trabalhos apresentados sobre suscetibilidade magnética, na área de ciência do solo, utiliza sensores próprios (Bartington Instruments, Witney, UK) (DEARING, 1999; PREETZ et al., 2008). Outros autores avaliaram a suscetibilidade magnética por meio do sistema desenvolvido por RANKINE (1934) e aprimorado por DAVIS (1992) utilizando uma balança analítica (CARNEIRO et al., 2003; CANO et al., 2008) e um magnetômetro (FABRIS et al., 1998). A vantagem em se utilizar o método da balança analítica é a simplicidade, permitindo sua utilização por pesquisadores e produtores de diferentes níveis de tecnificação.

Assim, o objetivo desse trabalho foi estudar o potencial da suscetibilidade magnética como função de pedotransferência para estimar atributos do solo utilizando uma balança analítica em um Argissolo sob cultivo de cana-de-açúcar. 


\subsection{MATERIAL E MÉTODOS}

\subsubsection{Localização da área e amostragem}

A área de estudo está localizada no município de Catanduva, SP, com coordenadas geográficas $21^{\circ} 05^{\prime} S$ e $49^{\circ} 01^{\prime} \mathrm{W}$. O clima da região foi classificado pelo método de Köppen, como tropical, quente e úmido, tipo Aw, seco no inverno, com precipitação média de $1350 \mathrm{~mm}$, com chuvas concentradas no período de novembro a fevereiro. A vegetação primária da região de Catanduva foi classificada como floresta pluvial estacional e cerrado, sendo o uso atual principalmente cana-de-açúcar, há mais de 20 anos em sistema de colheita pós-queimada.

O material de origem dos solos foi identificado como rocha arenítica sedimentar do Grupo Bauru, Formação Adamantina (IPT, 1981). O solo foi classificado como Argissolo Vermelho-Amarelo eutrófico / Typic Hapludalf (SOIL SURVEY STAFF, 1999) com $210 \mathrm{~g} \mathrm{~kg}^{-1}$ de argila e $760 \mathrm{~g} \mathrm{~kg}^{-1}$ de areia.

$\mathrm{Na}$ área o teor de ferro total $\left(\mathrm{Fe}_{2} \mathrm{O}_{3}\right)$, na profundidade de 0,0-0,2 $\mathrm{m}$, é de $18 \mathrm{~g} \mathrm{~kg}^{-1}$. Foram amostrados 50 pontos de forma aleatória em uma área de 2 ha, na profundidade de $0,00-0,20 \mathrm{~m}$.

\subsubsection{Avaliação dos atributos do solo e análise dos dados}

As amostras foram secas e peneiradas com peneiras de malha com diâmetro de $2 \mathrm{~mm}$ para análises granulométricas, químicas e mineralógicas. A granulométria foi determinada de acordo com a Lei de Stokes, pelo método da pipeta com solução de $\mathrm{NaOH}$ 0,1 N como dispersante químico e agitação mecânica em aparato de baixa velocidade por 16 horas, seguindo a metodologia proposta pela EMBRAPA (1997).

Os elementos presentes na solução do solo: cálcio $(\mathrm{Ca})$, magnésio $(\mathrm{Mg})$, potássio $(\mathrm{K})$ e hidrogênio+alumínio $(\mathrm{H}+\mathrm{Al})$, foram determinados de acordo com a metodologia proposta por RAIJ et al. (1987). O atributo saturação por bases (V\%) foi calculado. O teor de matéria orgânica foi obtido de acordo com o método descrito em 
EMBRAPA (1997). Os minerais hematita e goethita foram determinados conforme a metodologia descrita por CAMARGO et al. (2008).

A suscetibilidade magnética das amostras foi medida por um sensor da Bartington Instruments (DEARING, 1999) e por uma balança de precisão seguindo a metodologia descrita por CANO et al. (2008) (Figura 1).

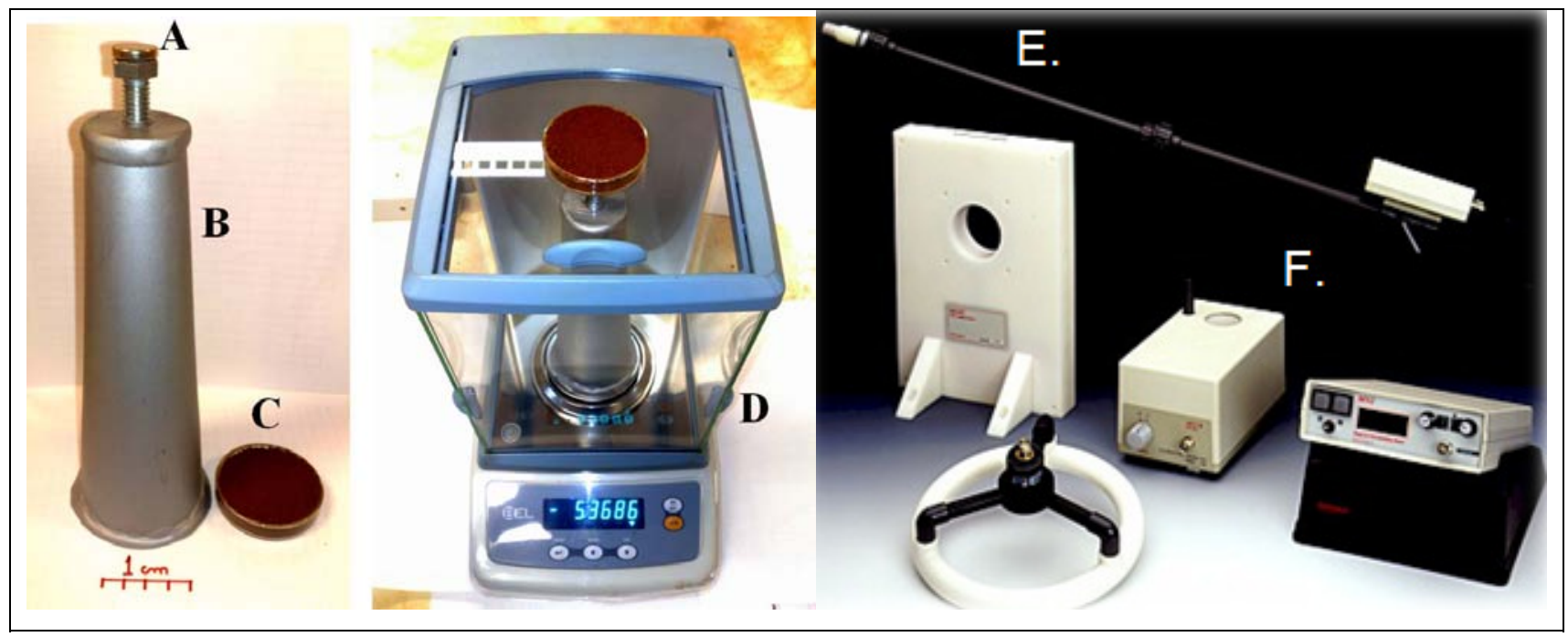

Figura 1. A. imã; B. Suporte; C. Porta amostra; D. Conjunto imã-suporte-porta amostra e balança (Metodologia adaptada de CARNEIRO et al., 2003); E. Sensor para avaliação da suscetibilidade magnética em campo; F. Sensor para avaliação da suscetibilidade magnética em laboratório.

A Tabela 1 mostra os reagentes utilizados na determinação da suscetibilidade magnética pela balança, assim como o valor de suscetibilidade magnética tabelada de cada reagente e o valor da força peso obtida na balança.

Os resultados da suscetibilidade magnética obtida pela balança foram comparados com os resultados da suscetibilidade magnética medidas pelo sensor da Bartington Instruments (Figura 2). 
Tabela 1. Modelo de regressão encontrado para converter força peso em suscetibilidade magnética molar utilizando uma balança analítica.

\begin{tabular}{|c|c|c|c|}
\hline $\begin{array}{l}\text { Reagentes utilizados para } \\
\text { fazer a curva de calibração }\end{array}$ & ${ }^{\mathrm{a}} \mathrm{FP}(\mathrm{kg})$ & $\begin{array}{c}{ }^{b} \mathrm{SMT}^{-} \\
\left(10^{-6} \mathrm{~cm}^{3} \mathrm{~mol}\right)\end{array}$ & Modelo de regressão \\
\hline Sulfato de zinco & 0,0021 & $-47,8$ & \\
\hline Sulfato de âmnio & 0,0024 & -67 & \\
\hline Cloreto de potássio & 0,0025 & $-38,8$ & $y=-01105 x+710^{-5}$ \\
\hline Sulfato ferroso & $-0,0972$ & 11200 & $y=-0,110 b x+710$ \\
\hline Sulfato de níquel & $-0,0432$ & 4005 & \\
\hline Acetato de sódio & 0,0014 & $-37,6$ & \\
\hline
\end{tabular}

Foi utilizada a densidade do solo para converter a suscetibilidade magnética molar $\left(\mathrm{mol} \mathrm{cm}{ }^{-3}\right)$ em suscetibilidade magnética mássica $\left(\mathrm{m}^{3} \mathrm{~kg}^{-1}\right)$. As medidas da suscetibilidade com o auxílio da balança analítica apresentaram resultados que confirmam a possibilidade do uso de sua técnica simples para avaliar a suscetibilidade nas amostras.

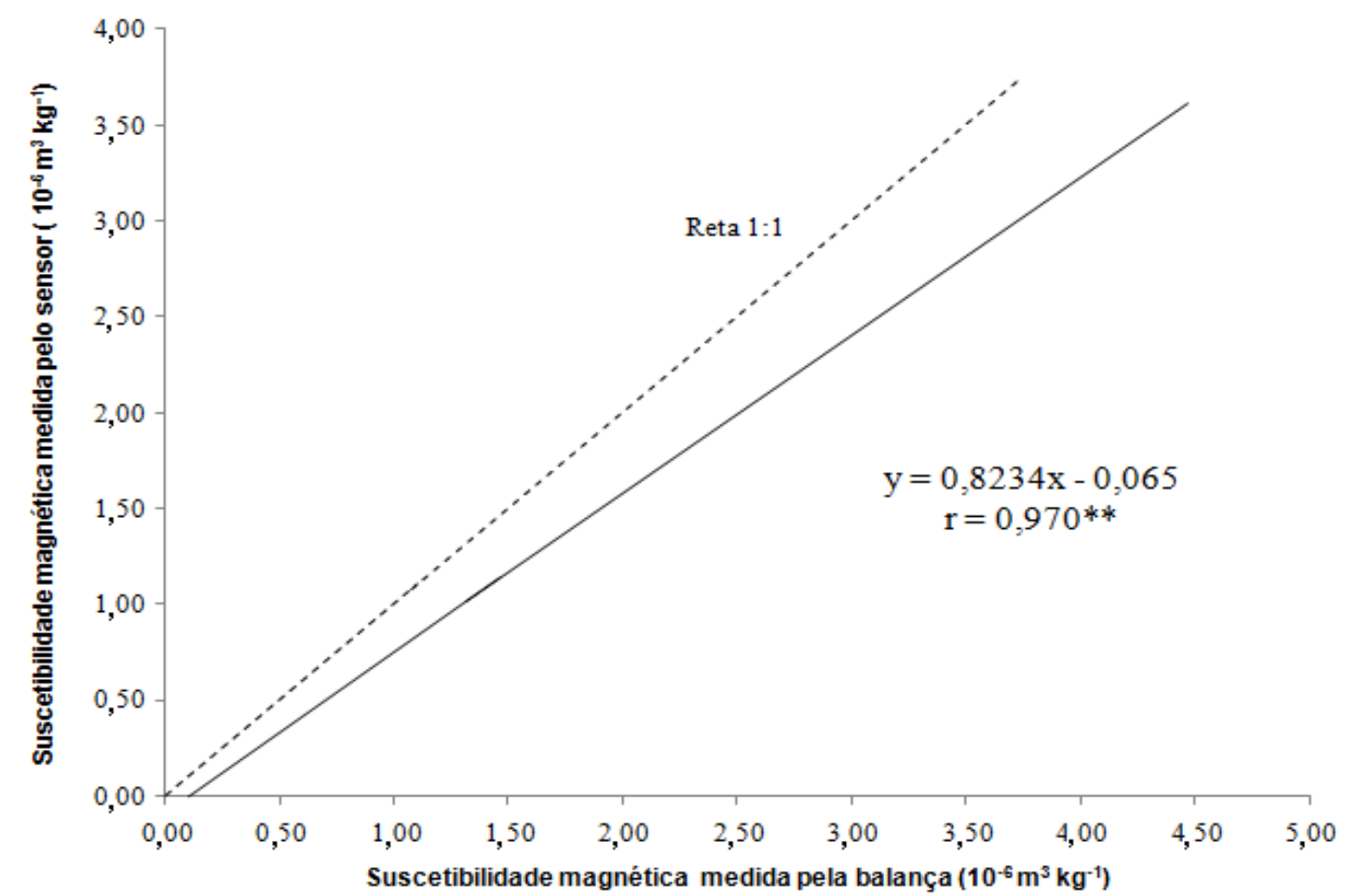

Figura 2. Comparação da suscetibilidade magnética medida pelo sensor e a estimada pelos modelos com ajuda da balança analítica (reta contínua). 
A diferença existente entre a reta 1:1 e a reta da SM estimada é devido à fonte magnética, pois enquanto o método da balança se utilizada de um imã com campo magnético constante o sensor tem um campo magnético alternado. O coeficiente de inclinação da reta $(0,82)$ próximo de 1 e o coeficiente linear $(-0,06)$ próximo de zero (Figura 2) indicam a coincidência entre os métodos de avaliação da SM.

Foi feita a análise de componentes principais para os atributos físicos, químicos, mineralógicos e da suscetibilidade magnética do solo obtida pela balança analítica. $O$ objetivo da ACP é encontrar, em um conjunto de dados, um atributo que seja capaz de explicar parte significativa da variância, por meio de correlações lineares (KHATTREE \& NAIK, 2000; MINGOTI, 2005; FERREIRA, 2008).

Com isso pode-se verificar a capacidade da suscetibilidade magnética medida por uma balança analítica em representar um conjunto de atributos físicos, químicos e mineralógicos do solo na profundidade de 0,00-0,20 m. Foram utilizados 40 pontos para construir modelos de regressão entre a SM medida pela balança e o teor de argila, V\% e teor de hematita no solo. Os 10 pontos restantes foram utilizados na validação externa dos modelos de regressão encontrados. Os valores estimados pelos modelos de regressão foram comparados com os valores reais dos atributos.

\subsection{RESULTADOS E DISCUSSÃO}

A suscetibilidade magnética (SM) avaliada pela balança analítica teve correlação com teor de argila, MO, hematita e V\% (Tabela 2). HANESCH \& SCHOLGER (2005), também encontraram correlações significativas da suscetibilidade magnéticas com atributos físicos e químicos de diferentes grupos de solos. MAHER (1998) encontraram uma correlação de suscetibilidade com carbono orgânico e argila. A presença de matéria orgânica favorece um aumento da suscetibilidade, pois proporciona as condições necessárias para a redução de ferro (MULLINS, 1977). 
Tabela 2. Correlação da suscetibilidade magnética com os atributos do solo na profundidade de $0,0-0,20$

\begin{tabular}{ll}
$\mathrm{m}$. & \\
\hline Teor de Argila & Saturação por bases \\
\hline $0,58^{\star *}$ & $0,41^{\star *}$ \\
\hline Matéria orgânica & Teor de hematita \\
\hline$-0,75^{\star *}$ & $0,82^{\star *}$ \\
\hline${ }^{* *}$ Significativo a $1 \%$ de probabilidade pelo teste t-student. &
\end{tabular}

${ }^{* *}$ Significativo a $1 \%$ de probabilidade pelo teste t-student.

SANTANA et al. (1999) postularam que, por meio de sucessivas oxidações de $\mathrm{Fe}^{2+}$ em $\mathrm{Fe}^{3+}$, é possível transformar magnetita em hematita, de menor expressão magnética nos solos. Segundo SCHWERTMANN (1988) e HANESCH et al. (2006) altas temperaturas e matéria orgânica favorecem a transformação do Fe pedogenético, causando a neoformação de minerais com característica magnética. Esse resultado indica que a suscetibilidade magnética pode ser utilizada como importante ferramenta no mapeamento de áreas com diferentes potenciais de emissão de $\mathrm{CO}_{2}$.

FONTES et al. (2000) mencionam que o comportamento magnético é mais evidente em solos cuja fração argila é maior. Isso ocorre porque, na fração areia, a magnetita é oxidada diretamente a hematita, enquanto que na fração argila a magnetita é oxidada em maghemita, que possui maior SM do que a hematita.

Foi encontrada uma correlação de 0,82 entre suscetibilidade magnética e o teor de hematita, indicando que a suscetibilidade magnética é maior nos locais com maior teor de hematita. Outros autores (CHEVRIER \& MATHÉ, 2007; TORRENT et al., 2007) também relatam sobre a relação da suscetibilidade magnética com atributos mineralógicos. Como os atributos físicos e químicos do solo são reflexo das características mineralógicas (HEREDIA \& CIRELLI, 2007; CAMARGO et al. 2008), a suscetibilidade magnética pode ser utilizada como medida indireta destes atributos. Segundo KÄMPF \& CURI (2000), os óxidos de ferro são importantes indicadores das condições ambientais, sendo estes minerais abundantes nos solos tropicais e de forte expressão no comportamento magnético dos solos, a suscetibilidade magnética mostrase como promissora medida qualitativa e quantitativa para auxiliar no mapeamento de áreas específicas de manejo.

Os resultados da ACP mostram que o componente principal (CP) 1 explica $41,92 \%$ da variância dos atributos do solo estudados (Figura 3). CARVALHO JUNIOR 
et al. (2008) trabalhando com análise multivariada de atributos físicos e químicos do solo encontraram que a CP 1 explica $28,29 \%$ da variância dos atributos. SPLECHTNA \& KLINKA (2001) também estudando atributos do solo mencionam que os fatores 1 e 2 explicam em torno de $60 \%$ da variação total do solo.

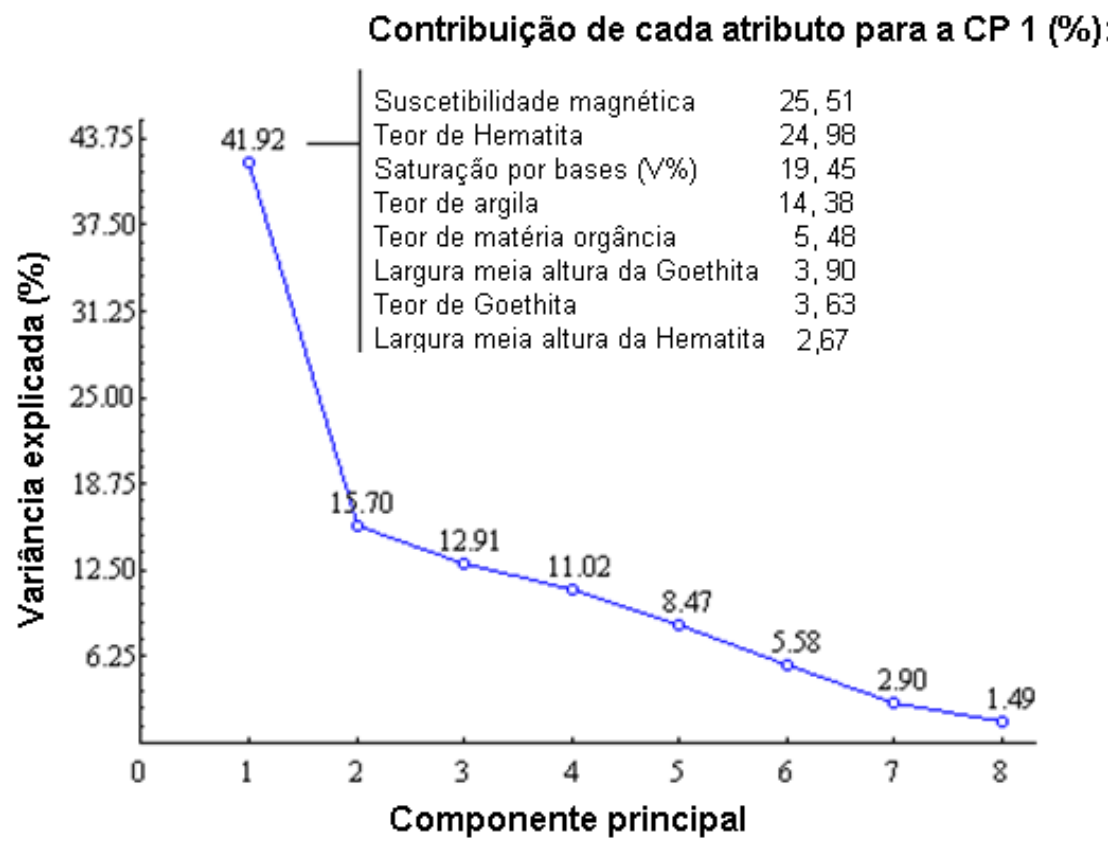

Figura 3. Gráfico da variância explicada do conjunto de variáveis por cada componente principal e contribuição de cada variável na composição do CP 1.

No CP 1 a SM foi o atributo de maior contribuição, com 25,51\%. Multiplicando a porcentagem de explicação pela contribuição da SM para a CP 1, encontra-se $10.69 \%$. Isso significa que a SM explica $10,69 \%$ da variância do conjunto de atributos do solo estudados. Vários autores tem utilizado a suscetibilidade magnética como indicadora das condições ambientais do solo (BOYKO et al., 2004) e em estudos sobre gênese e classificação dos solos (FABRIS et al., 1998; FONTES et al., 2000).

Os atributos teor de argila, V\% e teor de hematita estimados pelos modelos de regressão ficaram próximos dos valores reais determinados em laboratório (Figura 4). 

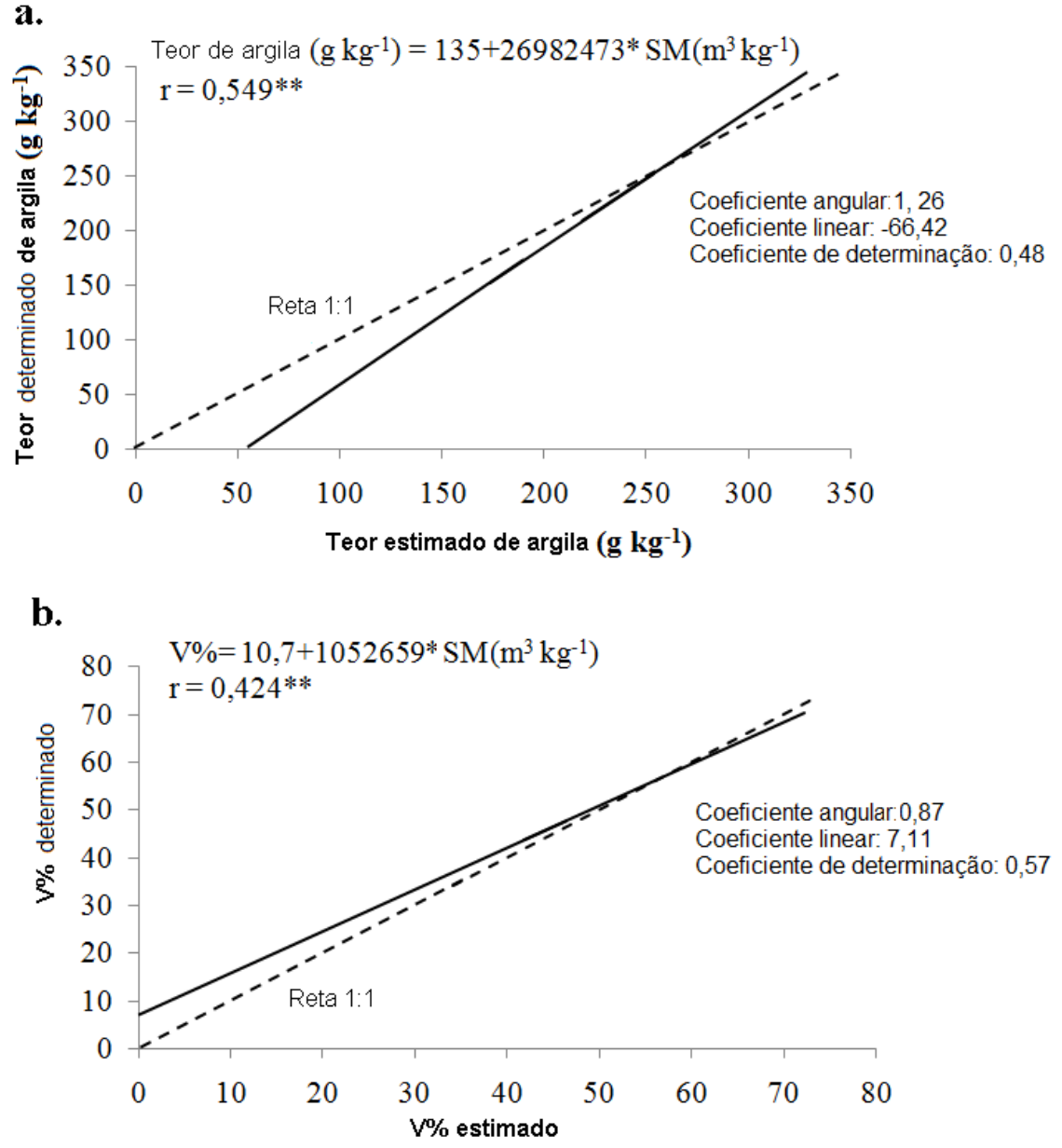

c.

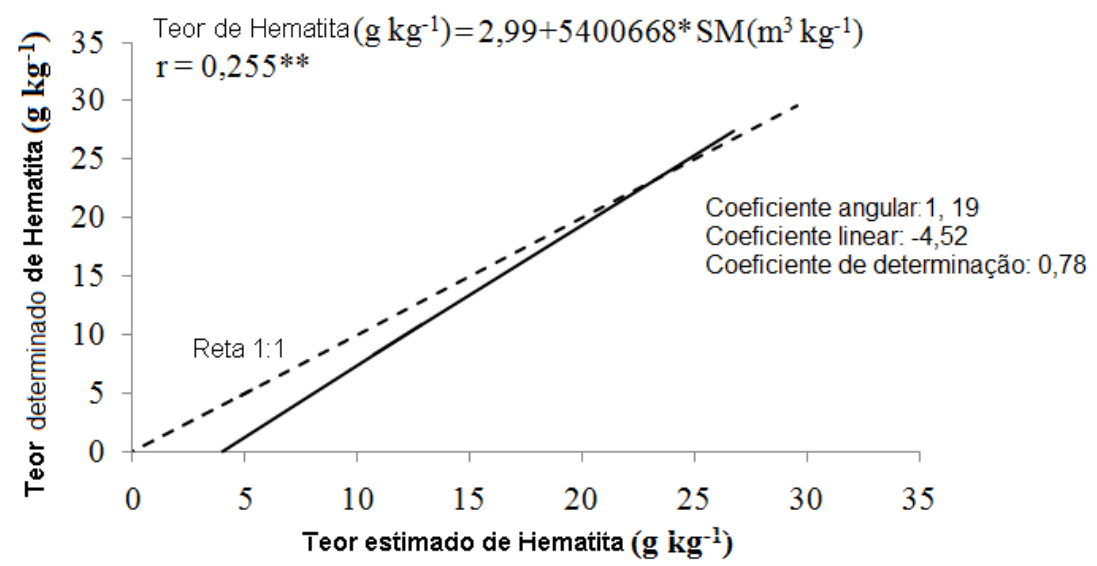

Figura 4. Validação cruzada dos modelos de regressão para determinação do teor de argila (a), V\% (b) e teor de hematita (c) do solo na profundidade de 0,0-0,20 m. A reta continua é referente à reta de tendência construída com base nos valores dos atributos do solo estimados pela suscetibilidade magnética. 
A proximidade com a reta 1:1 e os valores do teste de coincidência e paralelismo (coeficiente angular, linear e determinação) confirma a eficiência dos modelos de regressão. Dessa maneira a SM é capaz de explicar 30\% do teor de argila, 18\% da V\% e $6 \%$ do teor de hematita no solo. Alguns autores (MARQUES JR., 2009; SIQUEIRA et al., 2010) propõem a utilização de ferramentas como modelo digital de elevação, geoestatística, análise multivariada, e técnicas pedométricas como a refletância difusa e a suscetibilidade magnética para identificação de áreas específicas de manejo e estimar atributos do solo e culturas agrícolas.

Os resultados encontrados mostram que a avaliação da suscetibilidade magnética pode ser uma alternativa eficaz na determinação indireta de atributos do solo. A alta sensibilidade dessa metodologia é interessante no que se refere à identificação e mapeamento de ambientes com características específicas da região tropical, principalmente nas regiões com solos na transição arenito-basalto. Nestes locais muitas vezes o mapeamento equivocado dos atributos do solo, principalmente a cor, causa uma interpretação equivocada da variabilidade de diferentes classes de solos. Isso interfere nos estudos de causa e efeito sobre a resposta das culturas agrícolas e o ambiente em que estão inseridas.

\subsection{CONCLUSÕES}

1. Os resultados da suscetibilidade magnética obtidos com a balança mostram a possibilidade de uso da técnica e sua eficácia quando comparada a sensores específicos. Isso torna o método bastante atrativo para experimentos e aplicações práticas, visto que, o estudo de atributos geofísicos do solo, como o magnetismo, são pouco explorados devido à dificuldade instrumental.

2. A suscetibilidade magnética pode ser utilizada para auxiliar na estimativa do teor de argila, matéria orgânica, saturação por bases (V\%) e o teor de hematita de solos semelhantes aos do presente estudo. 


\subsection{REFERÊNCIAS}

BOYKO, T., SCHOLGER, R., STANJEK, H.,TEAM, M.Topsoil magnetic susceptibility mapping as a tool for pollution monitoring: repeatability of in situ measurements. Journal of Applied Geophysics, v.55,p.249-259, 2004.

BRENNING, A., KOSZINSKI, S, SOMMER, M. Geostatistical homogenization of soil conductivity across field boundaries. Geoderma, Amsterdam, v.143, p.254-260, 2008.

CAMARGO, L.A., MARQUES JR., J., PEREIRA, G.T., HORVAT, R.A. Variabilidade espacial de atributos mineralógicos de um latossolo sob diferentes formas do relevo: II correlação espacial entre mineralogia e agregados. Revista Brasileira de Ciência do Solo, Viçosa, v.32, p.2279-2288, 2008.

CANO, M.E., CORDOVA-FRAGA, T., SOSA, M., BERNAL-ALVARADO, J., BAFFA, O. Understanding the magnetic susceptibility measurements by using an analytical scale. European Journal Of Physics,v. 29,p.345-354, 2008.

CARNEIRO, A.A.O., TOUSO, A.T., BAFFA, O. Avaliação da suscetibilidade magnética usando uma balança analítica. Química Nova, v.26, p.952-956, 2003.

CARVALHO JUNIOR, W., SCHAEFER, C.E.G.R., CHAGAS, C.S.YF.F., ELPÍDIO, I. Análise multivariada de Argissolos da faixa atlântica brasileira. Revista Brasileira de Ciência Solo, Viçosa, v.32, p.2081-2090, 2008.

CHEVRIER, V., MATHÉ, P.E. Mineralogy and evolution of the surface of Mars: A review. Planetary and Space Science, v.55, p.289-314, 2007.

DAVIS, R.S. Using small, rare-earth magnets to study the susceptibility of feebly magnetic metals. American Journal of Physics, v. 60, p.365-370, 1992. 
DEARING, J.A. Environmental magnetic susceptibility: Using the Bartington MS2 system. 2nd ed. Chi Publ., Kenilworth, UK, 1999.

DEARING, J.A., HAY, K.L., BABAN, S.M.K., HUDDLESTON, A.S., WELLINGTON, E.M. H., LOVELAND, P.J. Magnetic susceptibility of soil: an evaluation of conicting theories using a national data set. Geophysical Journal International,v.127, p.728-734, 1996.

EMBRAPA. Manual de métodos de análise de solo. Rio de Janeiro: Ministério da Agricultura e do Abastecimento, 2 ed., pp 212, 1997.

FABRIS, J.D., COEY, J.M.D., MUSSEL, W.N. Magnetic soils from mafic lithodomains in Brazil. Hyperfine Interactions, v.113, p.249-258, 1998.

FERREIRA, D.F. Estatística Multivariada.Lavras; Editora UFLA, 1 ed., 662pp., 2008.

FONTES, M.P.F., OLIVEIRA, T.S., COSTA, L.M., CAMPOS, A.A.G. Magnetic separation and evaluation of magnetization of Brazilian soils from different parent materials. Geoderma, Amsterdam, v.96, p.81-99, 2000.

FROGBROOK, Z.L., OLIVER, M.A. Identifying management zones in agricultural fields using spatially constrained classification of soil and ancillary data. Soil Use And Management, v. 23, p.40-51, 2007.

GRIMLEY, D.A., ARRUDA, N.K., BRAMSTEDT, M.W. Using magnetic susceptibility to facilitate more rapid, reproducible, and precise delineation of hydric soils in the midwestern USA. Catena, Amsterdam, v.58, p.183-213, 2004. 
GRIMLEY, D.A., VEPRASKAS, M.J. Magnetic Susceptibility for Use in Delineating Hydric Soils. Soil Science Society of America Journal, Madison, v.64, p.2174-2180, 2000.

HANESCH, M., SCHOLGER, R. The influence of soil type on the magnetic susceptibility measured throughout soil profiles. Geophysical Journal International, v.161, p.50-56, 2005.

HANESCH, M., STANJEK, H., PETERSEN, N. Thermomagnetic measurements of soil iron minerals: The role of organic carbon. Geophysical Journal International, v. 165, p.53-61, 2006.

HEREDIA, O.S., CIRELLI, A.F. Environmental risks of increasing phosphorus addition in relation to soil sorption capacity. Geoderma, Amsterdam, v.137, p.426-431, 2007.

INSTITUTO DE PESQUISAS TECNOLOGICAS DO ESTADO DE SÃO PAULO (IPT), Mapa geomorfológico do Estado de São Paulo 1981. São Paulo, 94p.

JOHNSON, C.K., DORAN, J.W., DUKE, H.R., WIENHOLD, B.J., ESKRIDGE, K.M., SHANAHAN, J.F. Field-scale electrical conductivity mapping for delineating soil condition. Soil Science Society of America Journal, Madison, v. 65, p. 1829-1837, 2001.

KÄMPF, N., CURI, N. Óxidos de ferro: indicadores de atributos e ambientes pedogenéticos e geoquímicos. In: Tópicos em Ciência do Solo (eds Novais, RF, Alvarez, VVH \& Schaefer, CEGR) Viçosa, Sociedade Brasileira de Ciência do solo, pp.107-138, 2000 .

KHATTREE, R., NAIK, D.N. Multivariate Data Reduction and Discrimination with SAS Software. SAS Institute, Cary, NC, 2000. 
MAHER, B.A. Magnetic properties of modern soils and Quaternary loessic paleosols: paleoclimatic implications, Palaeogeog. alaeoclimat. Palaeoecol., v.137, p.25-54, 1998.

MAHER, B.A., THOMPSON, R. The magnetic record of palaeoclimate in the terrestrial loess and palaeosol sequences, in Quaternary Climates. In: Environments and Magnetism (eds Maher, BA \& Thompson, R). University Press, Cambridge, pp. 81-125, 1999.

MARQUES JR, J. Caracterização de áreas de manejo específico no contexto das relações solo-relevo. 2009. 113 f. Tese (Livre-Docência) - Faculdade de Ciências Agrárias e Veterinárias, Universidade Estadual Paulista, Jaboticabal, 2009.

MATHÉ, V., LÉVÊQUE, F., MATHÉ, P.E., CHEVALLIER, C., PONS, Y. Soil anomaly mapping using a caesium magnetometer: Limits in the low magnetic amplitude case. Journal of Applied Geophysics, v.58, p.202-217, 2006.

McBRATNEY, A.B., MINASNY, B., CATTLE, S.R., VERVOORT, R.W. From pedotranfer functions to soil inference systems. Geoderma, Amsterdam, v.109, p.41-73, 2002.

MINGOTI, S. A. Análise de dados através de métodos de estatística multivariada: uma abordagem aplicada. Belo Horizonte, 2005.

MULLINS, C.E. Magnetic susceptibility of the soil and its significance in soil science-a review, Journal Soil Science, v. 28, p.223-246, 1997.

PREETZ, H., ALTFELDER, S., IGEL, J. Tropical Soils and Landmine Detection-An Approach for a Classifi cation System. Soil Science Society of America Journal, Amsterdam, v.72, p.151-159, 2008. 
RAIJ, B. VAN.; QUAGGIO, J. A.; CANTARELLA, H. Análise química do solo para fins de fertilidade. Campinas: Fundação Cargill, 1987.

RANKINE, A.O. Proc. Phys. Soc., v.46, p.391, 1934.

SANTANA, G.P., DE JESUS FILHO, M.F., FABRIS, J.D., GOULART, A.T. Magnetite and its transformation to hematite in a pedosystem derived from steatite. Phys. Chem. Miner., _Submitted and accepted, 1999.

SCHWERTMANN, U. Occurrence and formation of iron oxides in various pedoenvironments. p. 267-308. In J.W. Stucki et al. (ed.) Iron in soils and clay minerals. Reidel Publ., Dordrecht, the Netherlands, 1988.

SCHWERTMANN, U. Occurrence and formation of iron oxides in various pedoenvironments. p. 267-308. In J.W. Stucki et al. (ed.) Iron in soils and clay minerals. Reidel Publ., Dordrecht, the Netherlands, 1988.

SILVA, F.D., COUCEIRO, .PR.C., FABRIS, J.D., GOULART, A.T., KER, J.C. Magnesioferrita e caminho pedogenético de transformação de óxidos de ferro magnéticos em dois perfis de solo derivados de tufito da Região do Alto Paranaíba (MG). Revista Brasileira de Ciência do Solo, Viçosa, v.29, p.763-775, 2005.

SIQUEIRA, D.S., MARQUES JR., J., PEREIRA, G.T. The use of landforms to predict the variability of soil and orange attributes. Geoderma v. 155, 55-66, 2010.

SOIL SURVEY STAFF SOIL TAXONOMY. A basic system of soil classification for making 404 and interpreting soil surveys, 2eds. USDA, NRCS, Washington, D.C., Agricultural 405 Handbook 436, 1999. 
SPLECHTNA, B.E., KLINKA, K. Quantitative characterization of nutrient regimes of highelevation forest soils in the southern coastal region of British Columbia, Canada. Geoderma, Amsterdam, v.102, p.153-174, 2001.

TORRENT, J., LIU, Q., BLOEMENDAL, J., BARRÓN, V. Magnetic enhancement and iron oxides in the upper Luochuan loess-paleosol sequence, Chinese Loess Plateau. Soil Science Society American Journal, Madison, v. 71, p.1-9, 2007.

VEROSUB, K.L., ROBERTS, A.P. Environmental magnetism: past, present and future Journal of Geophysical Research, v.100, p.2175-2192, 1995. 


\section{CAPÍTULO 3. MAPEAMENTO DE ÁREAS DE MANEJO ESPECÍFICO PARA A CANA-DE-AÇÚCAR UTILIZANDO A SUSCETIBILIDADE MAGNÉTICA DO SOLO}

Resumo - O objetivo do trabalho foi comparar a continuidade espacial da SM com atributos do solo e da cana-de-açúcar, para auxiliar o mapeamento de áreas de manejo especifico. Em uma área de 770 ha foram retiradas 110 amostras de solo aleatoriamente (grade irregular), em duas profundidades, $0,00-0,20 \mathrm{~m}$ e 0,20- 0,40 m, para avaliação dos atributos granulométricos, químicos e suscetibilidade magnética do solo. Dentro da área de 770 hectares foram avaliadas 32 sub-áreas com média de 68 hectares. Foi avaliado a produção, pol e porcentagem de fibra da cana-de-açúcar no ano de 2007. A dependência espacial dos atributos foi modelada por meio do semivariograma escalonado e correlação dos mapas de distribuição espacial. Os resultados indicaram que na delimitação dos limites para áreas de manejo especifico, a suscetibilidade magnética apresentou um erro de 33 a 50\% menor em relação aos atributos físicos e químicos do solo. Além disso, a suscetibilidade magnética apresentou correlação espacial significativa com os atributos do solo e da planta de cana-de-açúcar. Assim, a SM pode-se utilizada para auxiliar o mapeamento de áreas de manejo especifico para a cultura da cana-de-açúcar.

Palavras-chave: ambiente de produção, semivariograma escalonado, correlação espacial. 


\subsection{INTRODUÇÃO}

Segundo o Programa FAPESP de Pesquisa em Bioenergia (BIOEN, 2009) a expansão da produção de etanol no Brasil irá combinar ganhos de produtividade, com base na aplicaçao de novas tecnologias, e aumento da área plantada de cana de açúcar. Esse crescimento poderá gerar impactos negativos sobre o meio ambiente, sobre as relações sociais e de outras atividades econômicas. Nesse sentido, é importante analisar os riscos e propor métodos específicos ou políticas para evitar esses impactos.

$\mathrm{Na}$ agricultura o planejamento de uso e manejo do solo e a tomada de decisão são feitas com base nas suas análises químicas e físicas. As necessidades tecnológicas mais urgentes referentes ao manejo localizado do solo e ao mapeamento de solos estão relacionadas com desenvolvimento de métodos quantitativos dos atributos do solo que sejam mais rápidos e menos onerosos (RIVERO et al., 2007; CHRISTY, 2008) e que permitam identificar no campo limites mais precisos entre diferentes áreas de manejo.

Tentando resolver esse problema alguns pesquisadores (OFFICER et al., 2004) tentam representar a variabilidade das características do solo por meio de um único atributo que expresse as condições do ambiente. Em seu estudo OFFICER et al. (2004), compararam o mapa de fertilidade do solo com o mapa de condutividade elétrica, encontrando uma correlação significativa entre os tipos de mapas gerados. A condutividade elétrica expressa o comportamento de interação de vários atributos físicos e químicos do solo. Nesse sentido, as pesquisas envolvendo a geofísica como ferramenta pedométrica, mostra-se promissora, porém ainda são muito incipientes no Brasil (BECEGATO et al., 2005).

Outra técnica com grande potencial para o mapeamento e a quantificação indireta de atributos do solo é a suscetibilidade magnética (SM) (RESENDE et al., 1981; GRIMLEY \& VEPRASKAS, 2000; BECEGATO et al.,2005). Segundo MARQUES JR. (2009) nos locais onde há transição dos materiais de origem dos solos, como por exemplo na transição arenito-basalto, a avaliação da suscetibilidade magnética deve 
ser utilizada para melhorar a precisão e acurasse dos limites entre classes de solos. De acordo com o ultimo levantamento realizado pelo IPT em 1981, na escala 1:1.000.000, a transição arenito-basalto abrange aproximadamente 3,5 \% (873 mil ha) do Estado de São Paulo. Nessa região se localiza os principais Pólos sucroalcoleiros do Estado.

Além da quantificação indireta de atributos do solo, a SM pode ser utilizada para a identificação de áreas com diferentes potenciais de risco à erosão (ROYALL, 2001), emissão de $\mathrm{CO}_{2}$, aptidão quali-quantitativa da cultura da cana-de-açúcar (MARQUES JR., 2009). Assim, a suscetibilidade mostra-se promissora ferramenta no mapeamento destes locais, principalmente nos solos com presença de óxidos de ferro, que respondem pela magnetização do solo, especialmente os ferrimagneticamente ordenados, como magnetita e maghemita (SILVA et al., 2005). Porém, é necessária uma calibração de modelos usando a SM e as análises convencionais, para se determinar os níveis de acurácia das estimativas. Além disso, é preciso averiguar a validade do modelo para diferentes locais, para que se possa compreender a variabilidade espacial dos resultados e verificar seu potencial de uso na identificação de áreas de manejo específico.

Nos estudos que tem por objetivo investigar a variabilidade espacial de um conjunto de fatores ambientais o semivariograma escalonado é a ferramenta apropriada, pois é criado um único modelo da dependência espacial para um conjunto dos atributos do solo (CEDDIA et al., 2009; FERREYRA et al., 2002). Isto permite melhor compreensão da similaridade da distribuição espacial dos diferentes atributos estudados. Também é possível comparar o erro ou efeito pepita, que é a variância não explicada ou ao acaso, freqüentemente causada por erros de determinação no laboratório ou variações dos atributos que não podem ser detectadas na escala de amostragem.

Assim, o objetivo do trabalho foi comparar a continuidade espacial de atributos do solo e valores de SM medidas em amostras de solo em áreas sob cultivo da canade-açúcar, para auxiliar o mapeamento de áreas de manejo específico. 


\subsection{MATERIAL E MÉTODOS}

\subsubsection{Localização e caracterização da área}

A área de estudo de 770 ha localiza-se no nordeste do Estado de São Paulo, no

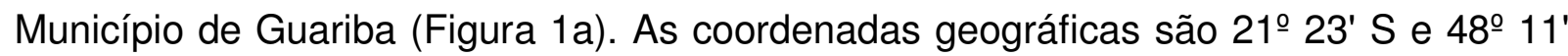
W, com altitude máxima de $674 \mathrm{~m}$ acima do nível do mar. O clima da região, segundo a classificação de Köppen, é do tipo mesotérmico com inverno seco (Cwa), com precipitação média de $1.400 \mathrm{~mm}$, com chuvas concentradas no período de novembro a fevereiro.

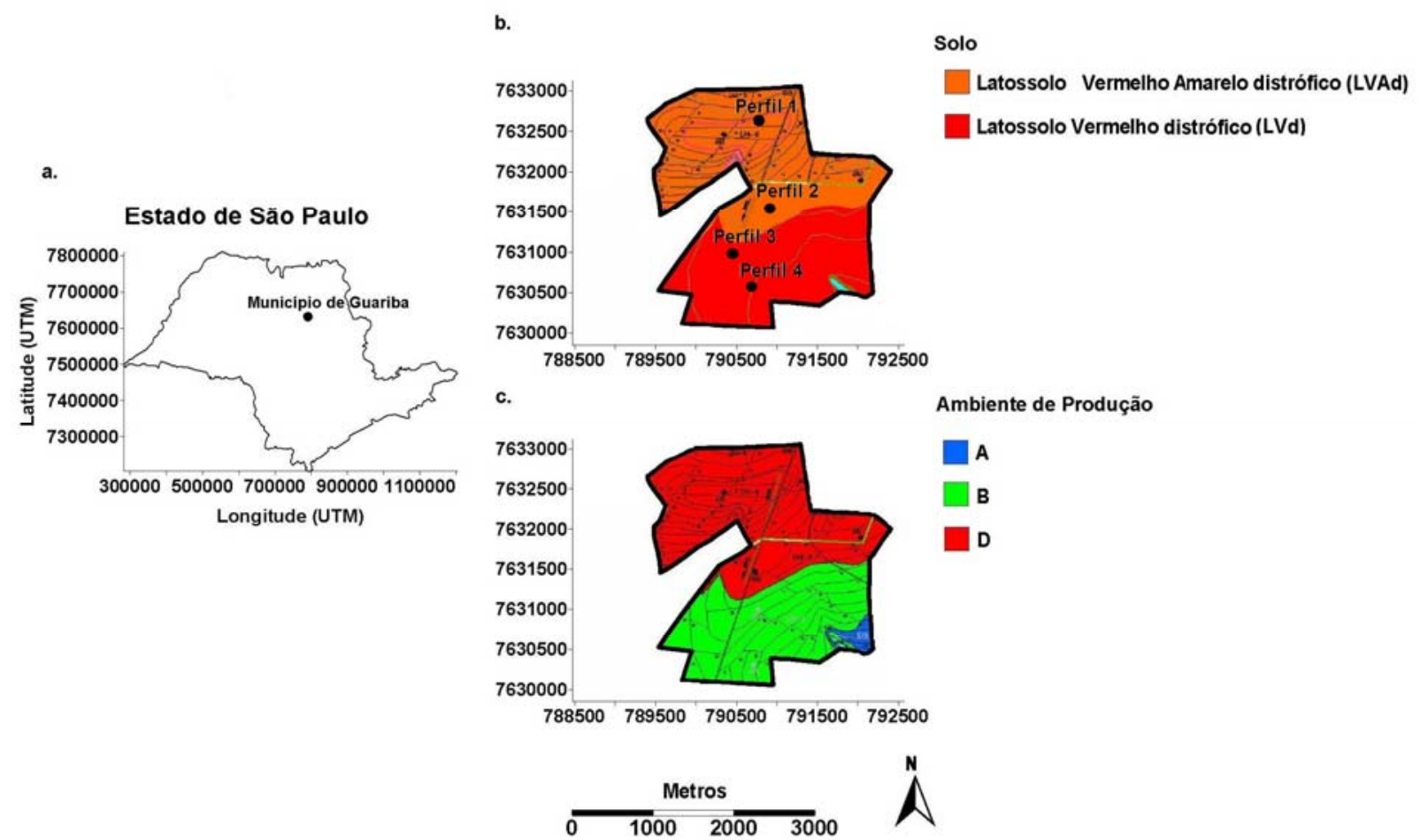

Figura 1. Localização da área (a), mapa de solos em nível detalhado (b) e mapa dos ambientes de produção para cana-de-açúcar (c). Perfil1, P2, P3 e P4= Perfis descritos na área; A= Ambiente de alta produtividade para cana-de-açúcar, $\mathrm{B}=$ Ambiente de alta/média produtividade para cana-de-açúcar, $\mathrm{D}=$ Ambiente de baixa produtividade para cana-de-açúcar

A vegetação natural era constituída por floresta tropical subcaducifólia, sendo o uso atual cultivo de cana-de-açúcar com sistema de colheita mecanizada. Esta área está inserida na província geomorfológica do Planalto Ocidental Paulista. O material geológico na área estudada está relacionado aos arenitos do Grupo Bauru, Formação 
Adamantina limítofre para o Basalto do Grupo São Bento Formação Serra Geral (IPT, 1981).

O mapa de solos da área de estudo, elaborado pelo Centro de Tecnologia Canavieira (CTC), registra a ocorrência do Latossolo Vermelho-Amarelo distrófico típico textura média (LVAd) e Latossolo Vermelho distrófico típico textura média (LVd), Para efeito de intensidade desse levantamento de solos, no atual estudo, foram descritas quatro trincheiras em uma transeção localizada na parte central da área (Figura 1b) segundo a metodologia proposta pela EMBRAPA (2006). O perfil 1 localiza-se no topo da paisagem, e os demais perfis distribuem-se ao longo do espigão na direção da encosta inferior (Figura 1b). Na Tabela 1 é apresentada a caracterização granulométrica e química dos perfis de solos descritos na área.

Tabela 1. Caracterização granulométrica e química dos solos ao longo da transeção .

\begin{tabular}{|c|c|c|c|c|c|c|c|c|c|c|c|}
\hline \multirow{2}{*}{ Perfil/Horizonte } & Profundidade & \multicolumn{2}{|c|}{$\mathrm{pH}$} & \multirow[t]{2}{*}{$\Delta \mathrm{pH}$} & \multirow{2}{*}{$\frac{\text { M.O. }}{\mathrm{g} \mathrm{dm}^{-3}}$} & \multirow{2}{*}{\multicolumn{2}{|c|}{$\begin{array}{l}\text { SB CTC } \\
\mathrm{mmol}_{\mathrm{c}} \mathrm{dm}^{-3}\end{array}$}} & \multirow{2}{*}{$\mathrm{V}$} & \multirow{2}{*}{\multicolumn{2}{|c|}{ Areia Silte }} & \multirow{2}{*}{ Argila } \\
\hline & $\mathrm{m}$ & $\mathrm{H}_{2} \mathrm{O}$ & $\mathrm{KCl}$ & & & & & & & & \\
\hline Perfil 1 & \multicolumn{11}{|c|}{ Latossolo Vermelho-amarelo distrófico textura argilosa (LVAd) } \\
\hline$A_{1}$ & $0,00-0,15$ & 7,4 & 6,6 & $-0,8$ & 32,84 & 66,1 & 78,1 & 85 & 649 & 58 & 293 \\
\hline $\mathrm{Bw}_{2}$ & $0,90-1,40$ & 5,0 & 4,3 & $-0,7$ & 11,33 & 7,6 & 38,4 & 20 & 570 & 69 & 361 \\
\hline Perfil 2 & \multicolumn{11}{|c|}{ Latossolo Vermelho-amarelo distrófico textura argilosa (LVAd) } \\
\hline$A_{1}$ & $0,00-0,20$ & 6,4 & 5,5 & $-0,9$ & 25,32 & 38,5 & 63,5 & 61 & 636 & 76 & 288 \\
\hline $\mathrm{Bw}_{2}$ & $0,85-1,30$ & 6,5 & 6,0 & $-0,5$ & 9,09 & 15,29 & 31,69 & 48 & 552 & 58 & 390 \\
\hline Perfil 3 & \multicolumn{11}{|c|}{ Latossolo Vermelho eutrófico textura argilosa (LVd) } \\
\hline$A_{1}$ & $0,00-0,15$ & 6,1 & 5,1 & $-1,0$ & 27,12 & 43,8 & 78,1 & 56 & 504 & 98 & 398 \\
\hline $\mathrm{Bw}_{2}$ & $1,00-1,40$ & 6,5 & 5,9 & $-0,6$ & 9,62 & 21,3 & 39,5 & 54 & 446 & 76 & 478 \\
\hline Perfil 4 & \multicolumn{11}{|c|}{ Latossolo Vermelho eutrófico textura argilosa (LVd) } \\
\hline$A_{1}$ & $0,00-0,20$ & 6,3 & 5,5 & $-0,8$ & 24,18 & 37,8 & 65,6 & 58 & 574 & 84 & 342 \\
\hline $\mathrm{Bw}_{2}$ & $0,90-1,40$ & 6,0 & 5,5 & $-0,5$ & 14,06 & 29,9 & 54,9 & 54 & 528 & 73 & 399 \\
\hline
\end{tabular}

A área é cultivada com cana-de-açúcar sob sistema de colheita sem queima a mais de 10 anos. Foram identificados três Ambientes de Produção: A, B e D (Tabela 2, Figura 1c). 
Tabela 2. Ambientes de produção de cana-de-açúcar na região Centro-Sul do Brasil (CTC, 2010).

\begin{tabular}{|c|c|c|c|}
\hline \multirow{2}{*}{ Características } & \multicolumn{3}{|c|}{ Ambientes de produção } \\
\hline & A & 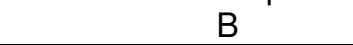 & D \\
\hline Atributos do solo & $\begin{array}{l}\text { ADA/M, e, f, m, } \\
\text { CTC média/alta }\end{array}$ & $\begin{array}{l}\text { ADA/M, e, f, m, } \\
\text { ma, CTC média/alta }\end{array}$ & $\begin{array}{r}\text { ADM/B, e, ma, } \\
\text { w, wf, CTC média/alta }\end{array}$ \\
\hline $\begin{array}{l}\text { Produtividade } \\
\text { (tonelada de cana ha }{ }^{-1} \text { ) }\end{array}$ & $>95$ & $90-95$ & $80-85$ \\
\hline
\end{tabular}

ADA: água disponível alta $\left(>1,0 \mathrm{~mm} \mathrm{~cm}^{-1}\right)$; ADM: água disponível média (entre 0,7-1,0 $\left.\mathrm{mm} \mathrm{cm}^{-1}\right)$; ADB: água disponível baixa $\left(<0,7 \mathrm{~mm} \mathrm{~cm}^{-1}\right)$; e: eutrófico $\left(\mathrm{V} \% \geq 50, \mathrm{SB} \geq 1,5 \mathrm{cmol}_{\mathrm{c}} \mathrm{kg}^{-1}\right)$; f: férrico (solos com teor de $\mathrm{Fe}_{2} \mathrm{O}_{3}$ entre 18 e 36\%), m: mesotrófico; ma: mesoálico (saturação por alumínio entre 15-50\%, $\mathrm{Al}_{3}+\geq 0,4 \mathrm{cmol}_{\mathrm{c}} \mathrm{kg}^{-1}$ ); w: ácrico (retenção de cátions $\leq 1,5 \mathrm{cmol}_{\mathrm{c}} \mathrm{kg}^{-1}$ ); wf: acriférrico; CTCalta: > $8 \mathrm{em} \mathrm{pH} \mathrm{7;}$ CTCmédia: entre 4 e 8 em pH 7.

O mapa de ambiente de produção para cana-de-açúcar (levantamento técnico) foi elaborado pela equipe do CTC com base no conhecimento das características inerentes a cada solo (levantamento taxonômico). No mapeamento dos ambientes de produção são levados em conta fatores edáficos e potencial de produção agrícola da cana-de-açúcar (MAULE et al., 2001; LEPSCH, 1987).

\subsubsection{Amostram e avaliação dos atributos do solo e da planta}

Foram coletadas 110 amostras de solo aleatoriamente (grade irregular) numa área de 770 ha nas profundidades de 0,00-0,20 m e 0,20- 0,40 m, cuja transeção ocupou a sua posição central. A maior distância entre dois pontos na área foi de aproximadamente $4.254 \mathrm{~m}$. Os pontos de amostragem foram georrefenrenciados, e a densidade amostral foi de 1 amostra a cada 7 ha.

As amostras foram secas e passadas em peneira de malha com diâmetro de 2 $\mathrm{mm}$ para análises granulométricas e químicas. A análise granulométria foi realizada pelo método da pipeta com solução de $\mathrm{NaOH} 0,1 \mathrm{~N}$ como dispersante químico e agitação mecânica em aparato de baixa velocidade por 16 horas, seguindo a metodologia proposta pela EMBRAPA (1997). As bases trocáveis cálcio (Ca), magnésio $(\mathrm{Mg})$, potássio $(\mathrm{K})$, e a acidez potencial $(\mathrm{H}+\mathrm{Al})$ foram realizados de acordo com a proposta de RAIJ et al. (1987).

Com base nos resultados das análises químicas, foi calculada a soma de bases (SB), capacidade de troca catiônica (CTC) e saturação por bases (V\%). O pH foi determinado potenciometricamente, utilizando-se $\mathrm{CaCl}_{2}$ 0,01 mol. $\mathrm{L}^{-1}(1: 2,5)$. Também foi 
determinado $\mathrm{pH}$ em água e $\mathrm{KCl}$ nas amostras dos perfis da área (Tabela 1). $\mathrm{O}$ teor de matéria orgânica foi obtido de acordo com o método descrito pela EMBRAPA (1997). A suscetibilidade magnética das amostras foi medida por uma balança de precisão seguindo a metodologia descrita por CANO et al. (2008). Esta metodologia estádescrita detalhadamente no capítulo 2.

Dentro da área de 770 hectares foram avaliadas 32 sub-áreas com média de 68 hectares. Nestas sub-áreas, no ano de 2007, foram avaliadas a produção de colmos por hectare, pol e porcentagem de fibra das plantas de cana-de-açúcar, segundo a metodologia proposta pelo CONSECANA (2003). As variedades plantadas foram SP813250 e a SP87-1365.

Estes atributos da cana-de-açúcar têm grande importância no controle industrial da fabricação de açúcar e de álcool, principalmente no que se refere à melhoria da eficiência do processo industrial, ao pagamento da cana-de-açúcar em função do teor de sacarose e à avaliação do estado de maturação da cana.

\subsubsection{Análise dos dados}

Foram calculados os valores de média, máximo, mínimo e coeficiente de variação para uma análise exploratória dos dados. Para determinação da existência da dependência espacial foram modelados semivariogramas. Com base nos parâmetros dos semivariogramas experimentais dos atributos do solo foi construído o semivariograma escalonado (VIERIA et al., 1997). O objetivo é representar vários semivariogramas simultaneamente para compreender melhor os padrões de similaridade e causas da variabilidade espacial (CEDDIA et al., 2009). O semivariograma escalonado foi calculado pela relação entre a semivariância original e o número de atributos estudados (EQUAÇÃO 1).

A análise da variabilidade espacial pelo semivariograma escalonado, auxilia em uma melhor representação da unidade amostral (COMEGNA \& BASILE, 1994; FERREYRA et al., 2002). Para os atributos da planta avaliados em um menor número 
de pontos, a interpolação foi feita utilizando como interpolador o inverso do quadrado da distância.

$$
\gamma_{\mathrm{i}}^{\mathrm{sc}}(\mathrm{h})=\frac{\gamma_{\mathrm{i}}(\mathrm{h})}{\alpha_{\mathrm{i}}} \quad \mathrm{i}=1,2, \ldots,
$$

onde,

$\mathrm{Yi}^{\mathrm{ic}}$ - semivariância do semivariograma escalonado na distância $\mathrm{h}$

yi - semivariância original na distância $h$

a - fator de escala, que pode ser assumido como o valor da variância ou do patamar, quando existir.

i - número de atributos estudados

Para investigar a similaridade da distribuição espacial dos atributos, foi feita a correlação espacial dos mapas da suscetibilidade magnética com os atributos do solo e da planta utilizado o critério empregado por JAKOB et al. (1999) e ROQUE et al. (2008).

\subsection{RESULTADOS E DISCUSSÃO}

$\mathrm{Na}$ Tabela 3 é apresentada a caracterização dos atributos do solo na área de estudo. A média dos valores do teor de argila e saturação por bases (V\%) determinados neste estudo, não corroboram com os valores desses atributos registrados no levantamento de solos realizado pelo CTC na mesma área. Assim, observa-se que estes estudos de intensidade realizados na área, registram a variabilidade desses atributos dentro da unidade de mapeamento do solo.

Segundo SOUZA et al. (2007) a variabilidade dos atributos do solo pode ser inferida por meio do coeficiente de variação (CV). De acordo com a classificação de WARRICK \& NIELSEN (1980) o atributo $\mathrm{pH}$ se enquadra na classe baixa (CV $\leq 12 \%)$, teor de argila, areia total e CTC enquadram-se na classe moderada $(12<$ CV <24) e SB, 
MO e SM enquadram-se na classe alta ( $C V \geq 24 \%)$, em ambas as profundidades. Dentre os atributos estudados a SM foi que apresentou maior CV. Isto reflete a grande sensibilidade deste atributo aos processos do solo que variam continuamente na paisagem. Segundo MATHÉ et al. (2006) a SM pode ser utilizada como micro indicadores das condições do solo.

Tabela 3. Caracterização granulométrica e química das amostras de solo coletadas na área de 770 ha (110 amostras).

\begin{tabular}{|c|c|c|c|c|c|}
\hline \multirow{2}{*}{\multicolumn{2}{|c|}{ Atributos do solo }} & Média & Máximo & Mínimo & $\mathrm{CV}^{8}$ \\
\hline & & \multicolumn{4}{|c|}{ Profundidade de $0,00-0,20 \mathrm{~m}$} \\
\hline Argila & $\left(\mathrm{g} \mathrm{kg}^{-1}\right)$ & 400,0 & 654 & 287 & 20,1 \\
\hline $\mathrm{AT}^{1}$ & $\left(\mathrm{~g} \mathrm{~kg}^{-1}\right)$ & 560,0 & 688 & 250 & 16,7 \\
\hline $\mathrm{SB}^{2}$ & $\left(\mathrm{mmol}_{\mathrm{c}} \mathrm{dm}^{-3}\right)$ & 40,6 & 62,8 & 8,5 & 24,6 \\
\hline CTC $^{3}$ & $\left(\mathrm{mmol}_{\mathrm{c}} \mathrm{dm}^{-3}\right)$ & 68,9 & 102,7 & 44,1 & 16,8 \\
\hline $\mathrm{V}^{4}$ & (\%) & 60 & 81,1 & 18,3 & 20 \\
\hline $\mathrm{MO}^{5}$ & $\left(\mathrm{~g} \mathrm{dm}^{-3}\right)$ & 12,3 & 30,0 & 1,8 & 79,3 \\
\hline $\mathrm{pH}$ & & 5,4 & 6,4 & 4,2 & 8,5 \\
\hline $\mathrm{SM}^{6}$ & $\left(10^{-6} \mathrm{~m}^{3} \mathrm{~kg}^{-1}\right)$ & 6,1 & 2,6 & 0,0 & 92,0 \\
\hline \multirow[t]{2}{*}{$\mathrm{Fe}_{2} \mathrm{O}_{3}{ }^{7}$} & $\left(\mathrm{~g} \mathrm{~kg}^{-1}\right)$ & 45,7 & 71,0 & 27,0 & 39,0 \\
\hline & & \multicolumn{4}{|c|}{ Profundidade de $0,20-0,40 \mathrm{~m}$} \\
\hline Argila & $\left(\mathrm{g} \mathrm{kg}^{-1}\right)$ & 449,0 & 676 & 330 & 18,2 \\
\hline AT & $\left(\mathrm{g} \mathrm{kg}^{-1}\right)$ & 513,0 & 640 & 234 & 18,7 \\
\hline SB & $\left(\mathrm{mmol}_{\mathrm{c}} \mathrm{dm}^{-3}\right)$ & 23,9 & 83,5 & 0,0 & 54,1 \\
\hline СТС & $\left(\mathrm{mmol}_{\mathrm{c}} \mathrm{dm}^{-3}\right)$ & 56,4 & 94,5 & 0,0 & 17,6 \\
\hline $\mathrm{V}$ & (\%) & 42 & 88,4 & 9,8 & 43 \\
\hline MO & $\left(\mathrm{g} \mathrm{dm}^{-3}\right)$ & 7,6 & 18,0 & 1,4 & 64,0 \\
\hline $\mathrm{pH}$ & & 4,8 & 6,3 & 3,8 & 12,0 \\
\hline SM & $\left(10^{-6} \mathrm{~m}^{3} \mathrm{~kg}^{-1}\right)$ & 6,3 & 2,7 & 0,0 & 88,8 \\
\hline $\mathrm{Fe}_{2} \mathrm{O}_{3}$ & $\left(\mathrm{~g} \mathrm{~kg}^{-1}\right)$ & 76,1 & 95,0 & 59,0 & 18,3 \\
\hline
\end{tabular}

1-Areia total; 2- Soma de bases; 3-Capacidade de retenção de cátions; 4-Saturação por bases; 5-Matéria orgânica; 6-Suscetibilidade magnética; 7-Ferro total levando em conta a amostragem de sete pontos; 8Coeficiente de variação (\%).

Estes resultados indicam que o levantamento de solo, utilizando valores médios, não representa adequadamente a variabilidade espacial dos atributos do solo.

Os resultados da Tabela 4 mostram que todos os atributos estudados possuem dependência espacial e apresentaram grau de dependência espacial (GDE) forte a moderado, segundo o critério proposto por CAMBARDELLA et al. (1994). Os atributos teor de argila, pH, MO e CTC apresentaram GDE moderado em ambas profundidades. Ressalta-se que o atributo SM, apresentou GDE alto na profundidade de 0,00-0,20 m e 
moderada na profundidade de $0,20-0,40 \mathrm{~m}$. Isto indica que os valores de SM estão relacionados com o local da paisagem e, portanto, com os processos de formação do solo que caracterizam este local. MAHER \& THOMPSON (1999), afirmam que os minerais com capacidade magnética armazenam arquivos naturais contendo registros dos fatores e processos de formação do solo.

De acordo com CAMBARDELLA et al. (1994) a variabilidade espacial de atributos do solo pode ser influenciada pelos seus fatores intrínsecos, e pelos fatores extrínsecos, normalmente empreendidos pelas práticas de manejo do solo. Neste sentido, o conceito de latossolos considera que seus atributos apresentam homogeneidade relativa ao longo de seu perfil na paisagem. Porém, observa-se que um latossolo sob cultivo há mais de 10 anos com a cultura da cana-de-açúcar não pode ser considerado homogêneo, uma vez que se observou variabilidade espacial para os atributos físicos e químicos.

Tabela 4. Parâmetros dos modelos de semivariogramas ajustados

\begin{tabular}{cccccccc}
\hline \multirow{2}{*}{ Atributos } & $\begin{array}{c}\text { Profundidade } \\
(\mathrm{m})\end{array}$ & Modelo & $\mathrm{C}_{0}$ & $\mathrm{C}_{0}+\mathrm{C}_{1}$ & $\mathrm{GDE}$ & $\begin{array}{c}\text { Alcance } \\
(\mathrm{m})\end{array}$ & $\mathrm{r}^{2}$ \\
& $0,00-0,20$ & Esférico & $310^{-12}$ & $1,310^{-11}$ & 23,08 & 1.700 & 0,68 \\
\multirow{2}{*}{ SM } & $0,20-0,40$ & Esférico & $4,610^{-12}$ & $1,710^{-11}$ & 27,06 & 1.650 & 0,88 \\
& $0,00-0,20$ & Exponencial & 15,00 & 47,00 & 31,91 & 1.500 & 0,87 \\
\multirow{2}{*}{ Argila } & $0,20-0,40$ & Esférico & 20,00 & 38,00 & 52,63 & 850 & 0,65 \\
& $0,00-0,20$ & Exponencial & 10,00 & 61,00 & 16,39 & 1.140 & 0,90 \\
Areia & $0,20-0,40$ & Exponencial & 15,00 & 48,50 & 30,93 & 630 & 0,59 \\
& $0,00-0,20$ & Exponencial & 0,08 & 0,18 & 44,44 & 1.260 & 0,60 \\
pH & $0,20-0,40$ & Esférico & 0,10 & 0,34 & 29,41 & 1.200 & 0,83 \\
& $0,00-0,20$ & Esférico & 28,00 & 88,00 & 31,82 & 1.500 & 0,93 \\
MO & $0,20-0,40$ & Esférico & 11,00 & 25,00 & 44,00 & 1.100 & 0,84 \\
& $0,00-0,20$ & Exponencial & 35,00 & 80,00 & 43,75 & 855 & 0,68 \\
SB & $0,20-0,40$ & Esférico & 45,00 & 185,00 & 24,32 & 1.000 & 0,99 \\
& $0,00-0,20$ & Esférico & 80,00 & 145,00 & 55,17 & 1.700 & 0,71 \\
CTC & $0,20-0,40$ & Esférico & 80,00 & 200,00 & 40,00 & 1.200 & 0,46 \\
\hline
\end{tabular}

$\mathrm{SM}=$ suscetibilidade magnética; $\mathrm{MO}=$ matéria orgânica; $\mathrm{SB}=$ soma de base; $\mathrm{CTC}=$ capacidade de troca de cátions; $\mathrm{C}_{0}=$ efeito pepita; $\mathrm{C}_{0}+\mathrm{C}_{1}=$ patamar; $\operatorname{GDE}\left(\mathrm{C}_{0} / \mathrm{C}_{0}+\mathrm{C}{ }^{*} 100\right)$ = grau de dependência espacial

Os valores de alcance variaram entre 630 e $1.700 \mathrm{~m}$. Este parâmetro pode ser interpretado como sendo a homogeneidade dos atributos na área. Assim, em relação à maior distância encontrada entre dois pontos na área $(4.254 \mathrm{~m})$, os resultados do 
parâmetro alcance sugerem homogeneidade de 15 a 40\%. Ressalta-se a proximidade entre os valores do parâmetro alcance da SM com os demais atributos do solo em ambas profundidades.

A modelagem dos semivariogramas escalonados para o conjunto de atributos do solo (argila, areia total, MO, pH, SB e CTC) nas profundidades de 0,00-0,20 m e 0,200,40 m, foi ajustado no modelo exponencial (Figura 2). VIERIA et al. (1997) ajustaram semivariograma escalonado no modelo esférico para de atributos físicos e químicos do solo. Já o atributo suscetibilidade magnética (SM), foi ajustado no modelo esférico, concordando com os estudos de MARQUES JR. (2009). A diferença básica entre o modelo exponencial e o esférico é que o exponencial atinge o patamar teoricamente (semivariância estabilizada). Logo, o parâmetro alcance do semivariograma não representa valores reais de campo com grande precisão, já o alcance encontrado pelo modelo esférico é o valor real. Isto indica que os limites reais de campo podem ser expressos com melhor acurácia e precisão quando identificados pela SM.

$\mathrm{Na}$ profundidade de 0,00-0,20 $\mathrm{m}$ o valor de alcance do semivariograma escalonado para o conjunto de atributos do solo foi de $1.600 \mathrm{~m}$. Nesta mesma profundidade a SM teve um alcance de $1.457 \mathrm{~m}$. Na profundidade de 0,20-0,40 $\mathrm{m} \mathrm{o}$ valor de alcance do semivariograma escalonado foi de $1.500 \mathrm{~m}$ para o conjunto de atributos do solo e $1.141 \mathrm{~m}$ para a SM. Isto indica uma similaridade no padrão de distribuição espacial entre o conjunto de atributos do solo e a SM em ambas as profundidades. BECEGATO et al. (2005) também encontraram similaridade entre o padrão de variabilidade espacial de atributos físicos e químicos do solo e a SM.

$\mathrm{O}$ valor de $\mathrm{C}_{0}$, variância não explicada (erro devido à amostragem, análise laboratorial, interpretação, etc) foi de 0,3 para o conjunto de atributos do solo e 0,15 para a SM na profundidade de 0,00-0,20 m. Na profundidade de 0,20-0,40 m o valor de $\mathrm{C}_{0}$ para semivariograma escalonado dos atributos do solo foi de 0,3 e da SM foi de 0,2. Este resultado mostra que o erro de representação da variabilidade espacial da SM foi de 33 a 50\% menor do que o conjunto de atributos do solo (Figura 2).

Neste sentido, a SM pode ser utilizada para aumentar a precisão e acurácia dos resultados de análises convencionais, contribuindo para a correta identificação de 
limites entre diferentes áreas no campo. Segundo MINASNY \& McBRATNEY (2008) a determinação de atributos encontrados em baixos teores no solo pode conter maior erro analítico laboratorial. CANTARELLA et al. (2006) relatam que erros em laboratórios são comuns, e que no Brasil, o erro de análises químicas está na faixa de 3 a $26 \%$ e das análises granulométricas entre 15 e 32\%. HARTEMINK (2007) menciona que o futuro da ciência do solo está no uso de técnicas indiretas para quantificação dos atributos do solo.

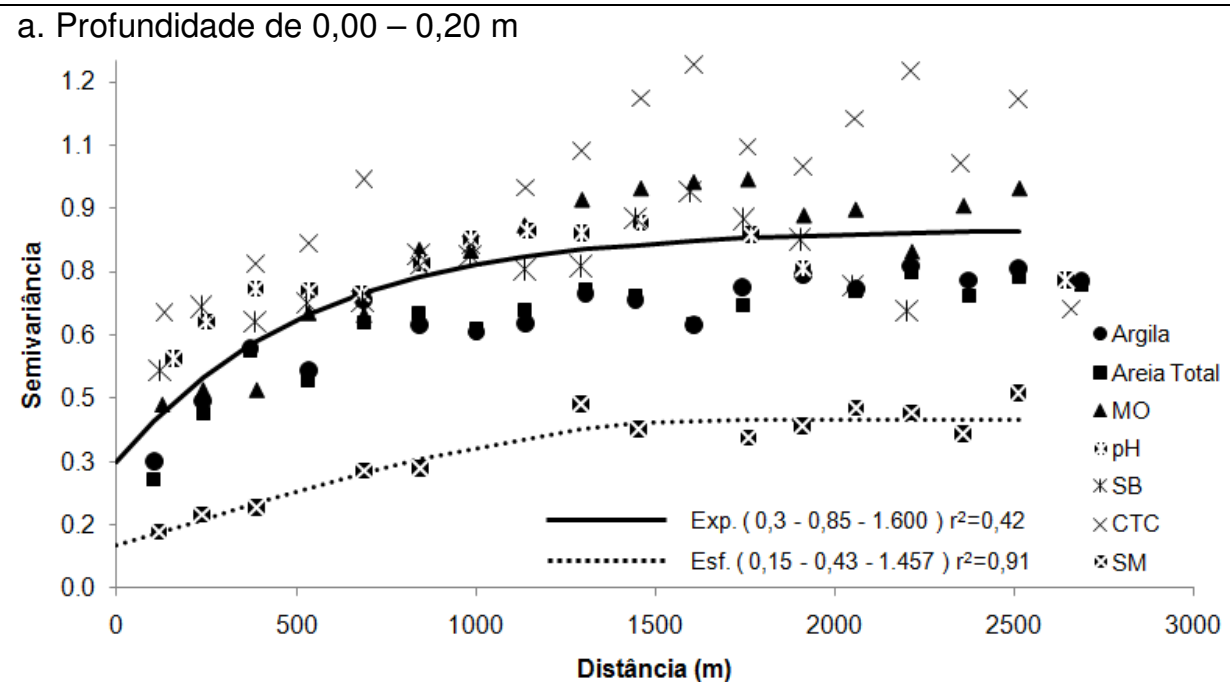

b. Profundidade de $0,20-0,40 \mathrm{~m}$

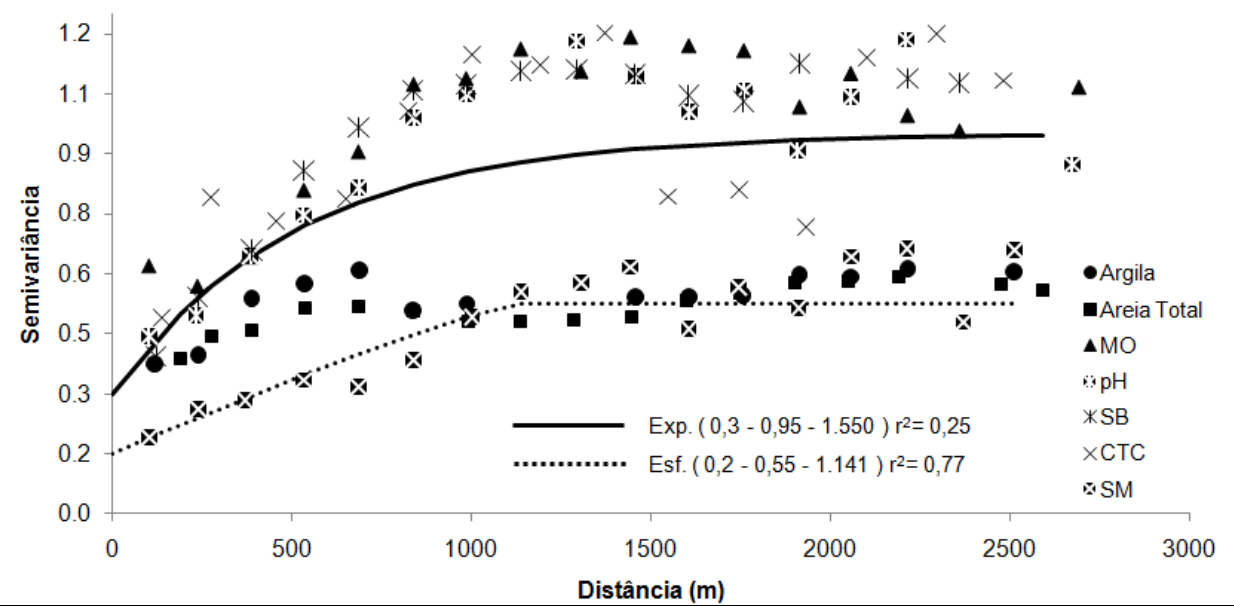

Figura 2. Semivariograma escalonado dos atributos do solo e parâmetros dos semivariogramas ajustados [modelo (efeito pepita - patamar - alcance)]. 
A vantagem de se utilizar o semivariograma escalonado no estudo da variabilidade espacial dos atributos do solo em relação a outras técnicas, como a do semivariograma cruzado (MCBRATNEY \& WEBSTER, 1986; CAMARGO et al. 2008), é a investigação do erro embutido na representação da estrutura da variabilidade espacial de diferentes atributos.

Nas Figuras 3 e 4 são apresentados os mapas de distribuição espacial dos atributos do solo e da planta. O mapa de solos indica que os solos de ocorrência na área enquadram-se na classe de textura média (entre 15 e 35\% de argila). Porém, observando o mapa de distribuição espacial do teor de argila, a área pode ser dividida nas classes de textura média e argilosa (entre 35 e 60\% de argila). Isto indica que no mapa de variabilidade espacial são encontradas um maior número de classes texturais do que a indicada pelo levantamento de solos (Figura 1b).

O Latossolo Vermelho Amarelo distrófico (LVAd) apresentou menor SM (Figura 3) do que o Latossolo Vermelho (LVd). A área está numa região limítofre entre Arenito e Basalto. O aumento da SM do LVAd para o LVd indica proximidade com o basalto que possui minerais com maior SM. FABRIS et al. (1998) e FONTES et al. (2000) mostraram a variabilidade da SM em função de diferentes materiais de origem, concluindo que a SM é sempre maior em solos originados de rochas basálticas, em relação às sedimentares. Nesse sentido, antes de estabelecer áreas específicas de manejo com auxílio na SM do solo, recomenda-se um conhecimento prévio dos materiais de origem na área.

Os resultados mostram que dentro de uma única classe de solo e ambiente de produção para cana-de-açúcar (Figura 1b e 1c), existe variabilidade dos atributos do solo e da planta (Figuras 3 e 4). Assim, a SM pode ser utilizada como técnica auxiliar para refinar os limites reais de campo em escalas mais detalhadas.. JOHNSON \& RICHARD (2005) ressaltam que os mapas de distribuição dos atributos do solo devem ser comparados com os mapas das características da cana-de-açúcar para promover uma maior eficiência nas praticas agrícolas e industriais. 


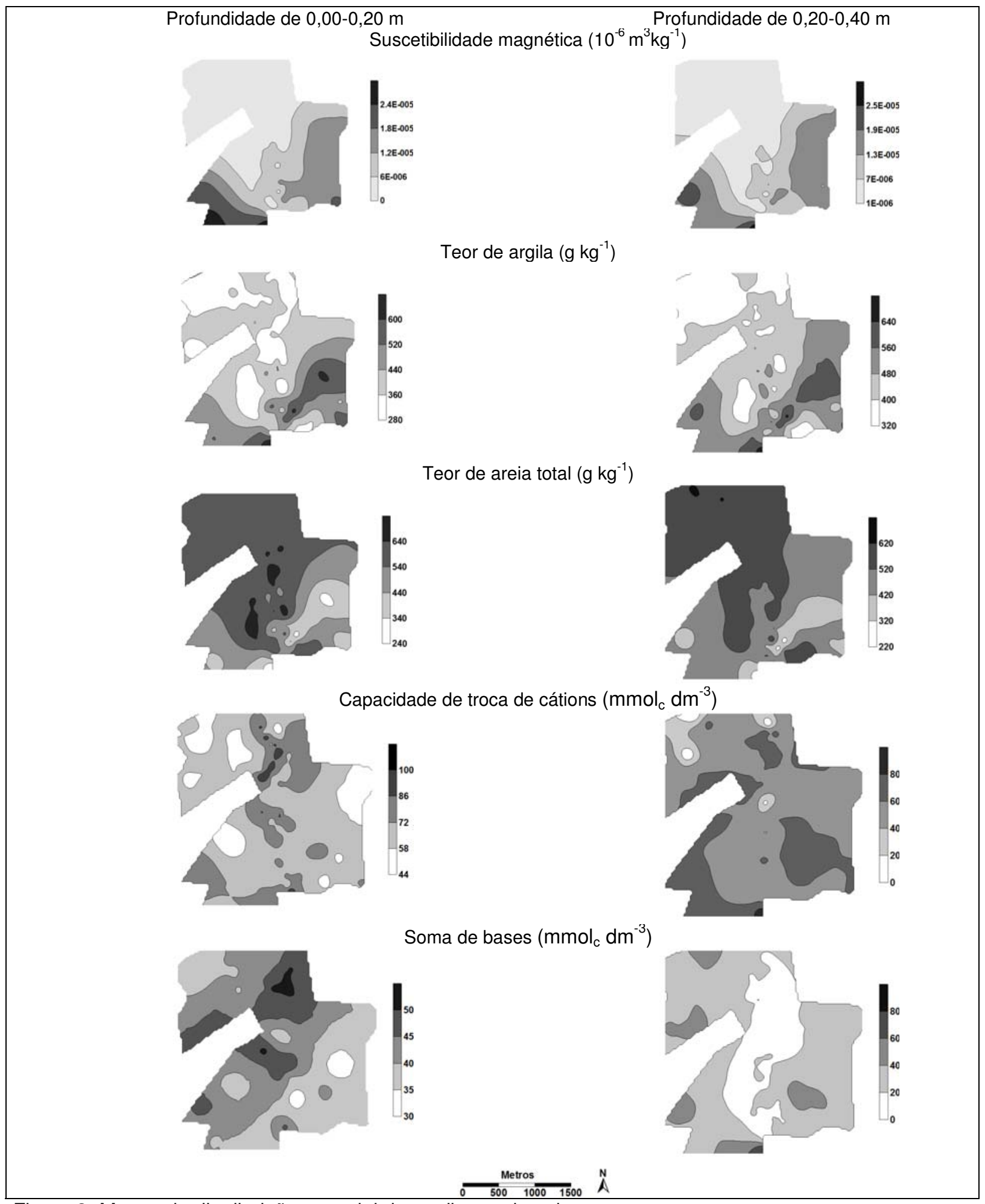

Figura 3. Mapas de distribuição espacial dos atributos do solo. 


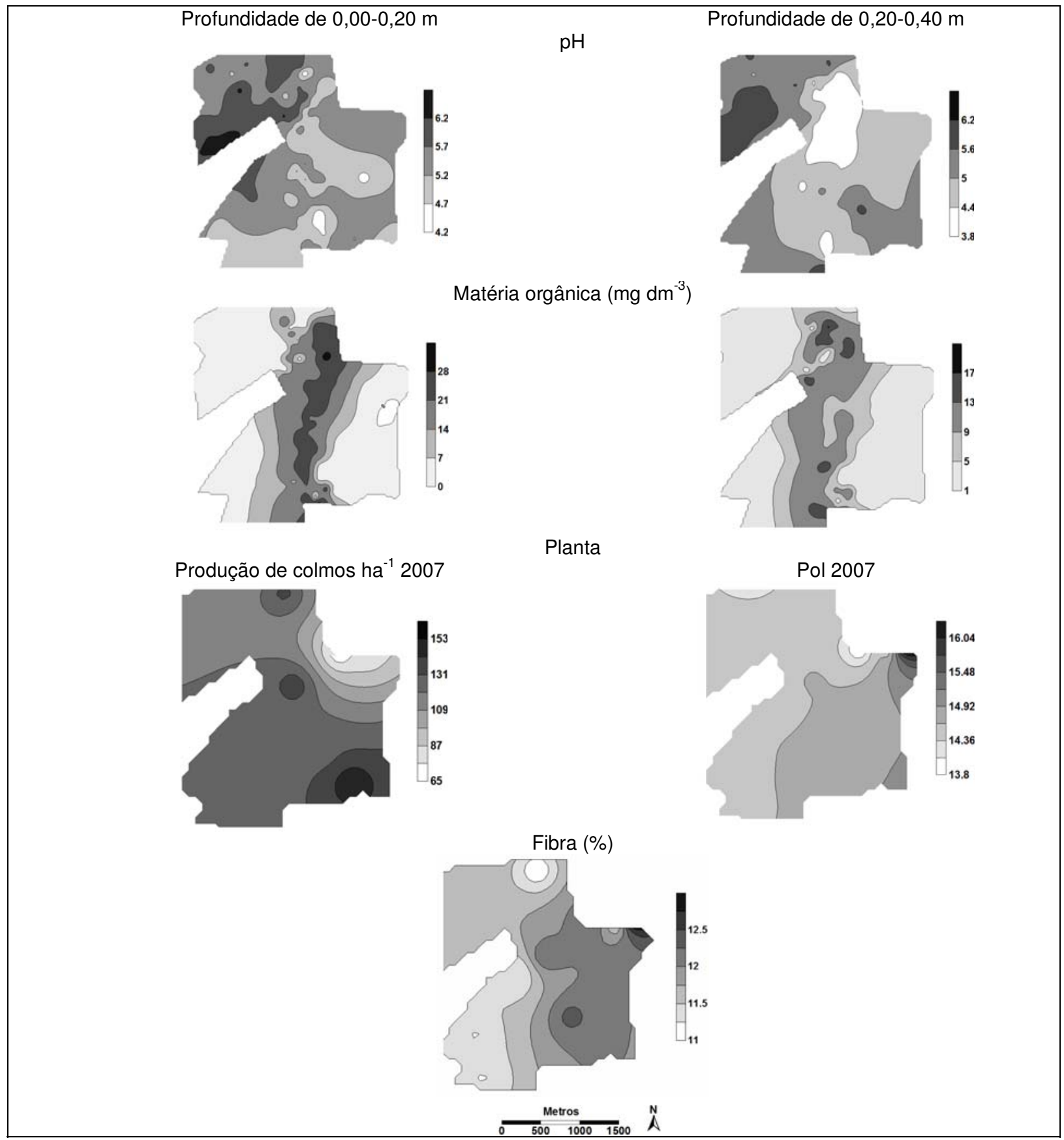

Figura 4. Mapas de distribuição espacial dos atributos do solo e da planta.

Comparando o mapa dos ambientes de produção (Figura 1c) com os mapas da SM e atributos da planta no ano de 2007 (Figura 4), nota-se que os ambientes de maior 
potencial para produção e qualidade industrial coincidem com os locais na paisagem com maiores valores de SM.

$\mathrm{Na}$ Tabela 4 é apresentada a correlação linear do mapa (pixel-a-pixel) da SM com os mapas de distribuição espacial dos atributos do solo e da planta. A SM apresentou maior correlação espacial com o teor de argila. BECEGATO (2005) também encontrou similaridade entre os mapas de SM e teor de argila nas profundidades de 0,00-0,20 e 0,20-0,40 m. FONTES et al. (2000) também encontraram maiores valores das propriedades magnéticas na fração argila do solo. Algumas pesquisas (AYYUB et al., 1988, CHEN et al., 2002; CHERNYSHOVA et al. 2007) sugerem que as mudanças estruturais entre hematita e maghemita são relacionadas ao tamanho das partículas do solo. Isso ocorre porque na fração areia, a magnetita é oxidada diretamente em hematita, enquanto que na fração argila a magnetita é oxidada em maghemita, que possui maior SM do que a hematita.

O estudo da distribuição espacial da SM relacionando-a com outros atributos do solo tem grande importância no que se refere à melhor compreensão da pedogênese (TORRENT et al., 2006). Isso traz informações valiosas sobre as condições de formação do solo em determinado local. Dessa maneira podem-se relacionar as propriedades magnéticas de minerais no solo com o local (MAHER \& THOMPSON, 1992; BANERJEE et al., 1993).

Tabela 4. Correlação espacial entre a suscetibilidade magnética e atributos do solo e da cana-de-açúcar.

\begin{tabular}{|c|c|c|}
\hline \multirow{3}{*}{ Atributos } & \multicolumn{2}{|c|}{ Suscetibilidade magnética } \\
\hline & $0,00-0,20 \mathrm{~m}$ & $0,20-0,40 \mathrm{~m}$ \\
\hline & \multicolumn{2}{|c|}{ Solo } \\
\hline Teor de argila & $0,828^{* *}$ & $0,887^{* *}$ \\
\hline Areia total & $-0,839^{* *}$ & $-0,883^{\star *}$ \\
\hline CTC & $0,218^{* *}$ & $0,475^{\star \star}$ \\
\hline SB & $-0,463^{\star *}$ & $0,369^{* *}$ \\
\hline $\mathrm{pH}$ & $-0,520^{* *}$ & $0,131^{\star *}$ \\
\hline \multirow[t]{2}{*}{ MO } & $-0,250^{* *}$ & $-0,355^{\star *}$ \\
\hline & \multicolumn{2}{|c|}{ Planta } \\
\hline Produtividade 2007 & $0,262^{\star *}$ & $0,235^{\star \star}$ \\
\hline POL 2007 & $0,426^{\star *}$ & $0,528^{\star *}$ \\
\hline Fibra 2007 & $-0,016$ & $0,085^{\star}$ \\
\hline
\end{tabular}

${ }^{\star}$ Significativo a $5 \%$ de probabilidade pelo teste t-student.

** Significativo a $1 \%$ de probabilidade pelo teste t-student. 
A CTC apresentou correlação espacial positiva com a SM, pois ambos são influenciados diretamente pela mineralogia dos solos. Solos altamente intemperizados, como latossolos, têm uma quantidade elevada de óxidos e hidróxidos de $\mathrm{Al}$ e $\mathrm{Fe}$ (SCHWERTMANN \& TAYLOR, 1989). Dessa maneira, correlacionando a CTC do solo com a SM pode-se ter uma estimativa do potencial de variação de troca de cargas de um determinado local. Esse resultado mostra que a SM é uma técnica promissora identificar ambientes com diferentes potenciais de adsorção de íons e moléculas (ALVES et al., 2004; BARBIERI et al., 2009).

Os atributos da cana-de-açúcar, no ano de 2007, tiveram correlação positiva com a SM. Resultados contrários foram encontrados por MARQUES JR. (2009), que encontrou correção negativa entre o POL e a SM. Ressalta-se que o atributo qualitativo (POL) teve melhor correlação com a SM do que o atributo quantitativo (produtividade). Neste sentido, comparando-se os mapas dos atributos da planta, (Figura 4) com a distribuição espacial da SM, pode-se estabelecer que para valores de POL entre 16,3 e 14,4 a SM varia de $610^{-6}$ a $1,810^{-5} \mathrm{~m}^{3} \mathrm{~kg}^{-1}$ na profundidade de $0,00-0,20 \mathrm{~m}$ e de $710^{-6}$ a $1,910^{-5} \mathrm{~m}^{3} \mathrm{~kg}^{-1}$ na profundidade de 0,20-0,40 m.

A SM tem sido utilizada na pela ciência do solo brasileira desde da década de 60 nos primeiros levantamentos de solo do estado de São Paulo, porém com finalidade qualitativa ( RESENDE et al,. 1988). Com base nos resultados encontrados, no presente estudo, está técnica se mostra promissora nos estudos de ciência do solo voltados a quantificação indireta de outros atributos do solo e da cana-de-açúcar.

\subsection{CONCLUSÕES}

1. A suscetibilidade magnética apresentou menor erro na representação da variabilidade espacial dos atributos do solo, e correlação espacial significativa com os atributos físicos e químicos do solo e os atributos da cana-de-açúcar.

2. A SM auxilia na compreensão da relação de causa e efeito entre solo e planta. 


\subsection{REFERÊNCIAS}

ALVES, P. L. C. A., MARQUES JR., J; FERRAUDO, A. S. Atributos de solos e a eficiência do sulfentrazone no controle de tiririca (Cyperus rotundus L.). Scientia Agricola, Piracicaba, v. 61, p. 319-325, 2004.

AYYUB, P., MULTANI, M., BARMA, M., PALKAR, V.R., VIJAYARAGHAVAN, R. Sizeinduced structural phase transitions and hyperfine properties of microcrystalline $\mathrm{Fe}_{2} \mathrm{O}_{3}$. Journal of Physics C-Solid State Physics, v.21, p.2229-2245, 1998.

BANERJEE, S.K., HUNT, C.P. AND LIU, X.P. Separation of local signals from the regional paleomonsoon record of the Chinese Loess Plateau: a rock-magnetism approach. Geophysical Research Letters, v.20, p.843-846, 1993.

BARBIERI, D. M; MARQUES JR., J.; ALLEONI, L. R. F.; GARBUIO, F. J.; CAMARGO, L. A. Hillslope curvature, clay mineralogy, and phosphorus adsorption in an Alfisol cultivated with sugarcane. Scientia Agrícola, Piracicaba, v.66, n.6, p. 819-826, 2009.

BECEGATO, V. A., FERREIRA, F. J. F. Gamaespectrometria, resistividade elétrica e suscetibilidade magnética de solos agrícolas no noroeste do estado do Paraná. Revista Brasileira de Geofísica, v.23, p.371-405, 2005.

CAMARGO, L. A.; MARQUES JUNIOR, J.; PEREIRA, G. T.; HORVAT, R. A. Variabilidade espacial de atributos mineralógicos de um latossolo sob diferentes formas do relevo: II - correlação espacial entre mineralogia e agregados. Revista Brasileira de Ciência do Solo, v.32, n.6, p. 2279-2288, 2008.

CAMBARDELLA, C.A.; MOORMAN, T.B.; NOVAK, J.M.; PARKIN, T.B.; KARLEN, D.L.; TURCO, R.F.; KONOPKA, A.E. Field-scale variability of soil properties in Central lowa Soils. Soil Science Society of America Journal, Madison, v.58, n.5, p.1501-1511, 1994. 
CANO, M.E., CORDOVA-FRAGA, T., SOSA, M., BERNAL-ALVARADO, J., BAFFA, O. Understanding the magnetic susceptibility measurements by using an analytical scale. European Journal Of Physics,v. 29,p.345-354, 2008.

CANTARELLA, H.; QUAGGIO, J. A.; RAIJ, B. Van.; ABREU, M.F. Variability of soil analysis in commercial laboratories: implications for lime and fertilizer recommendations. Communications in Soil Science and Plant Analysis, London, v. 37, p. 2213-2225, 2006.

CEDDIA, M. B.; VIEIRA, S. R.; VILLELA, A. L. O.; MOTA, L. S.; ANJOS, L. H. C.; CARVALHO, D. F. Topography and spatial variability of soil physical properties, Scientia Agricola, Piracicaba, v.66, n.3, p. 338-352, 2009.

CHEN, L.X., LIU, T., THURNAUER, M.C., CSENCSITS, R. AND RAJH, T. $\mathrm{Fe}_{2} \mathrm{O}_{3}$ nanoparticle structures investigated by X-ray absorption near-edge structure, surface modifications and model calculations. Journal of Physical Chemistry, v.106, p.85398546, 2002.

CHERNYSHOVA, I.V., HOCHELLA JR, M.F. AND MADDEN, A.S. Size-dependent structural transformations of hematite nanoparticles.1. Phase transition. Physical Chemistry Chemical Physics,v. 9, p.1736-1750, 2007.

CHRISTY, C.D. Real-time measurement of soil attributes using on-the-go near infrared reflectance spectroscopy. Computers and Electronics in Agriculture, Amsterdam, v. 61, p. 10- 19, 2008.

COMEGNA, V., BASILE, A. Temporal stability of spatial patterns of soil water storage in a cultivated Vesubian soil, Geoderma, Amsterdam, v.62, p.299-310, 1994. 
CONSECANA. Conselho dos Produtores de Cana-de-açúcar, açúcar e álcool do Estado de São Paulo. Manual de instruções. Piracicaba, 2003. 118 p.

CTC-Centro de Tecnologia Canavieira. Carta de Solos e Ambientes de Produção. Revista Coplana, p. 24-25, 2008. Disponível em: http://www.coplana.com/gxpfiles/ws001/design/RevistaCoplana/2008/Marco/pag2425.pdf; Acessado em: 03/02/2010.

EMBRAPA, EMPRESA BRASILEIRA DE PESQUISA AGROPECUÁRIA. Manual de métodos de análise de solo. 2. ed. Rio de Janeiro: Ministério da Agricultura e do Abastecimento, 1997. p. 212.

EMBRAPA. Centro Nacional de Pesquisa de Solos. Sistema brasileiro de classificação de solos.2. ed. Rio de Janeiro, 2006. p. 306.

FABRIS, J.D., COEY, J.M.D., MUSSEL, W.N. Magnetic soils from mafic lithodomains in Brazil. Hyperfine Interactions, v.113, p.249-258, 1998.

FERREYRA, R. A., APEZTEGUÍA, H. P., SERENO, R., JONES, J.W. Reduction of soil water spatial sampling density using scaled semivariograms and simulated annealing. Geoderma, Amsterdam, v.110, p. 265-289, 2002.

FONTES, M.P.F., OLIVEIRA, T.S., COSTA, L.M., CAMPOS, A.A.G. Magnetic separation and evaluation of magnetization of Brazilian soils from different parent materials. Geoderma, Amsterdam, v.96, p.81-99, 2000.

GOLUCHOWSKA, B. J. Some factors affecting an increase in magnetic susceptibility of cement dusts. J Appl Geophys v.48, p.103-112, 2001. 
GRIMLEY, D. A.; VEPRASKAS, M. J. Magnetic Susceptibility for Use in Delineating Hydric Soils. Soil Science Society of America Journal, Madison, v. 64, n. 6, p. 21742180, 2000.

GRIMLEY, D.A.; ARRUDA, N.K.; BRAMSTEDT, M.W. Using magnetic susceptibility to facilitate more rapid, reproducible and precise delineation of hydric soils in the midwestern USA. Catena. v.58, p.183-213, 2004.

HARTEMINK, A. E. El futuro Del La ciência Del suelo, 165pp., 2007.

INSTITUTO DE PESQUISAS TECNOLOGICAS DO ESTADO DE SÃO PAULO (IPT), Mapa geomorfológico do Estado de São Paulo 1981. São Paulo, 94p.

JAKOB, A. A. E.; ROCHA, J. V.; LAMPARELLI, R. A. C. Estudo da correlação entre mapas de variabilidade de propriedades do solo e mapas de produtividade para fins de agricultura de precisão. In: Congresso e Feira Para Usuários De Geoprocessamento Da América Latina-Gis Brasil 99, 5., 1999, Salvador. Anais Salvador: UFBA, 1999.

JOHNSON, R. M., RICHARD, E. P. JR. Sugarcane Yield, Sugarcane Quality, and Soil Variability in Louisiana. Agronomy Journal, v.97, p.760-771, 2005.

KAPICKA, A. JORDANOVA, N. PETROVSKÝ, E. USTJAK, S. Effect of different soil conditions on magnetic parameters of power-plant fly ashes. J Appl Geophys, v.48, p.93-102, 2001.

LEPSCH, I.F. Influência dos fatores edáficos na produção. In: CASTRO, P.R.C.; FERREIRA, S.O.; YAMADA, T. (Coord.) Ecofisiologia da produção. Piracicaba: Associação Brasileira para Pesquisa da Potassa e do Fosfato, 1987. p.83-98. 
MAHER, B.A., THOMPSON, R. Mineral magnetic record of the Chinese loess and palaeosols. Geology, v.19, p.3-6, 1991.

MAHER, B. A.; THOMPSON, R. (Ed.). Palaeomonsoons I: the magnetic record of palaeoclimate in the terrestrial loess and palaeosol sequences, in Quaternary Climates, Environments and Magnetism, Cambridge: University Press, p. 81-125, 1999.

MAHER, B.A.; ALEKSEEV, A.; ALEKSEEVA, T. Magnetic mineralogy of soils across the Russian Steppe: climatic dependence of pedogenic magnetite formation, Palaeogeog. Palaeoclimat. Palaeoecol., v. 201, p. 321-341, 2003.

MARQUES JR, J. Caracterização de áreas de manejo específico no contexto das relações solo-relevo. 2009. 113 f. Tese (Livre-Docência) - Faculdade de Ciências Agrárias e Veterinárias, Universidade Estadual Paulista, Jaboticabal, 2009.

MAULE, R. F., MAZZA, J. A., MARTHA JR., G. B. Produtividade agrícola de cultivares de cana-de-açúcar em diferentes solos e épocas de colheita. Scientia. Agrícola, Piracicaba, v. 58, p.295-301, 2001.

MATHÉ, V.; LÉVÊQUE, F.; MATHÉ, P. E.; CHEVALLIER, C.; PONS, Y. Soil anomaly mapping using a caesium magnetometer: Limits in the low magnetic amplitude case. Journal of Applied Geophysics, Amsterdam, v. 58, n. 3, p. 202-217, 2006.

McBRATNEY, A.B. \& WEBSTER, R. Choosing functions for semi-variograms of soil properties and fitting them to sampling estimates. Journal Soil Science, v.37, p.617-639, 1986.

MINASNY,B., McBRATNEY, A.B. Regression rules as a tool for predicting soil properties from infrared reflectance spectroscopy. Chemometrics and Intelligent Laboratory Systems, Amsterdam, v.94, p.72-79, 2008. 
OFFICER, S. J.; KRAVCHENKO, A.; BOLLERO, G. A; SUDDUTH, K. A.; KITCHEN, N. R.; WIEBOLD, W. J.; PALM, H. L.; BULLOCK, D. G. Relationships between soil bulk electrical conductivity and the principal component analysis of topography and soil fertility values. Plant Soil. v. 258, p.269-280, 2004.

Programa FAPESP de Pesquisa em Bioenergia (BIOEN). Disponível em: http://bioenfapesp.org/; Acessado em: 20/12/2009.

RAIJ, B. VAN.; QUAGGIO, J. A.; CANTARELLA, H. Análise química do solo para fins de fertilidade. Campinas: Fundação Cargill, 1987.

RESENDE, M. SANTANA, D. P. REZENDE, S. B. Susceptibilidade magnética em Latossolo do sudeste e sul do Brasil. In Anais da 3. Reunião de Classificação, correlação de solos e interpretação de aptidão agrícola. Rio de Janeiro, EMBRAPASNLCS/SBCS, 1988.

RIVERO, R.G; GRUNWALD, S; BRULAND, G.L. Incorporation of spectral data into multivariate geostatistical models to map soil phosphorus variability in a Florida wetland. Geoderma, Amsterdam, v.140. p.428-443, 2007.

ROQUE, M. W.; MATSURAII, E. E.; SOUZA, Z. M . S; BIZARI, D. R.; SOUZA, A. L. Correlação linear e espacial entre a resistência do solo ao penetrômetro e a produtividade do feijoeiro irrigado. Revista Brasileira de Ciência do Solo, v.32, n.5, p. 1827-1835, 2008.

ROYALL, D. Use of mineral magnetic measurements to investigate soil erosion and sediment delivery in a small agricultural catchment in limestone terrain. Catena, Amsterdam, v.46,p.15-34, 2001. 
SCHWERTMANN, U.; TAYLOR, R.M. Iron oxides. In: DIXON, J.B.; WEED, S.B., eds. Minerals in soil environments. 2.ed. Madison, Soil Science Society of America, 1989. p.379-438. (Book Series, 1)

SIQUEIRA, D.S., MARQUES JR., J., PEREIRA, G.T. The use of landforms to predict the variability of soil and orange attributes. Geoderma v. 155, 55-66, 2010.

SOUZA, Z. M.; BARBIERI, D. M.; MARQUES JUNIOR, J.; PEREIRA, G. T.; CAMPOS, M. C. C. Influência da variabilidade espacial de atributos químicos de um Latossolo na aplicação de insumos para cultura de cana-de-açúcar. Ciência. Agrotecnologia, Lavras, v. 31, n. 2, p. 371-377, 2007.

TORRENT, J., BARRÓN, V. AND LIU, Q. Magnetic enhancement is linked to and precedes hematite formation in aerobic soil. Geophysical Research Letters, 2006. doi:10.1029/2005GL024818.

TRANGMAR, B. B.; YOST, R. S.; UEHARA, G. Application of geostatistics to spatial studies of soil properties. Advances in Agronomy, San Diego, v. 38, p. 54-94, 1985.

VIEIRA, S.R.; TILLOTSON, P.M.; BIGGAR, J.W.; NIELSEN, D.R. Scaling of semivariograms and the kriging estimation of field-measured properties. Revista Brasileira de Ciência do Solo, Viçosa, v.21, n.4, p.525-33, 1997.

WARRICK, A.W.; NIELSEN, D.R. Spatial variability of soil physical properties in the field. In: HILLEL, D. (ed.). Applications of soil physics. New York: Academic, 1980. Cap.2, p.319-344. 